\title{
Spatial and Temporal Characteristics of Error-Related Activity in the Human Brain
}

\author{
Maital Neta, ${ }^{1}$ Francis M. Miezin, ${ }^{2,3,7}$ Steven M. Nelson, ${ }^{9}$ Joseph W. Dubis, ${ }^{2}$ Nico U.F. Dosenbach, ${ }^{2}$ \\ Bradley L. Schlaggar, ${ }^{2,3,4,5}$ and Steven E. Petersen ${ }^{2,3,5,6,7,8}$ \\ ${ }^{1}$ Department of Psychology, University of Nebraska-Lincoln, Lincoln, Nebraska 68588, Departments of ${ }^{2}$ Neurology, ${ }^{3}$ Radiology, ${ }^{4}$ Pediatrics, ${ }^{5}$ Anatomy and \\ Neurobiology, and ${ }^{\circ}$ Neurosurgery, Washington University School of Medicine, Departments of ${ }^{7}$ Psychology and ${ }^{8}$ Biomedical Engineering, Washington \\ University, St Louis, Missouri 63110, and ${ }^{9}$ VISN 17 Center of Excellence for Research on Returning War Veterans, Waco, Texas 76711
}

A number of studies have focused on the role of specific brain regions, such as the dorsal anterior cingulate cortex during trials on which participants make errors, whereas others have implicated a host of more widely distributed regions in the human brain. Previous work has proposed that there are multiple cognitive control networks, raising the question of whether error-related activity can be found in each of these networks. Thus, to examine error-related activity broadly, we conducted a meta-analysis consisting of 12 tasks that included both error and correct trials. These tasks varied by stimulus input (visual, auditory), response output (button press, speech), stimulus category (words, pictures), and task type (e.g., recognition memory, mental rotation). We identified 41 brain regions that showed a differential fMRI BOLD response to error and correct trials across a majority of tasks. These regions displayed three unique response profiles: (1) fast, (2) prolonged, and (3) a delayed response to errors, as well as a more canonical response to correct trials. These regions were found mostly in several control networks, each network predominantly displaying one response profile. The one exception to this "one network, one response profile" observation is the frontoparietal network, which showed prolonged response profiles (all in the right hemisphere), and fast profiles (all but one in the left hemisphere). We suggest that, in the place of a single localized error mechanism, these findings point to a large-scale set of error-related regions across multiple systems that likely subserve different functions.

Key words: error; functional networks; meta-analysis; resting state; task control

\section{Introduction}

A pervasive component of human cognition is the potential for errors of both omission and commission. Even when performing simple tasks, a lapse in attention or accidental touch of a button can result in an incorrect response. In the absence of explicit feedback, errors are associated with a variety of processes, including emotional reactions (Kiehl et al., 2000), and adjustments that may improve performance, including heightened attention (Posner and Petersen, 1990; Orr and Weissman, 2009) and slower subsequent responses (i.e., posterror slowing; Rabbitt, 1966). As such, a deeper understanding of the neural processes that under-

Received April 1, 2014; revised Oct. 29, 2014; accepted Nov. 3, 2014.

Author contributions: M.N., F.M.M., S.M.N., J.W.D., and S.E.P. designed research; M.N., F.M.M., S.M.N., J.W.D. and N.U.F.D. performed research; M.N., F.M.M., S.M.N., and J.W.D. analyzed data; M.N., F.M.M., S.M.N., N.U.F.D., B.L.S., and S.E.P. wrote the paper.

This work was supported by NIH R21 NS61144 (S.E.P.), NIH R01 NS26424 (S.E.P.), a McDonnell Foundation Collaborative Activity Award (S.E.P.), NIH R01 HD057076 (BLS), Hope Center for Neurological Disorders Pilot Award (B.L.S., S.E.P., N.U.F.D.), a Child Neurology Foundation PERF Scientific Research Award (N.U.F.D.), NIH U54 MH091657 (Van Essen), and the Intellectual and Developmental Disabilities Research (enter at Washington University (NIH/NICHD P3O HD062171). N.U.F.D. is a Scholar of the Child Health Research Center at Washington University School of Medicine (K12-HD076224). We thank Jonathan D. Power and Jordan A. Taylor for fruitful discussions about results, Haoxin Sun for discussion about methodological approaches, Timothy 0. Laumann and Babatunde Adeyemo for assistance with figures, and Deanna J. Greene for some discussion about conclusions.

The authors declare no competing financial interests.

Correspondence should be addressed to Maital Neta, B84 East Stadium, Center for Brain, Biology, and Behavior, University of Nebraska-Lincoln, Lincoln, NE 68588-0156. E-mail: maitalneta@unl.edu.

DOI:10.1523/JNEUROSCI.1313-14.2015

Copyright $\odot 2015$ the authors $\quad 0270-6474 / 15 / 350253-14 \$ 15.00 / 0$ lie error-related responses would contribute to findings in both cognitive psychology and cognitive neuroscience.

Although several regions have been found to show errorrelated activity (Hester et al., 2004; Tunik et al., 2005; Nelson et al., 2010; Ullsperger et al., 2010; e.g., anterior insula, thalamus, intraparietal sulcus, and inferior parietal lobule), much of the work on error responses has focused on the dorsal anterior cingulate (dACC), which often is shown to extend dorsally into the medial superior frontal cortex. In particular, the dACC is thought to be the source of the error-related negativity, an error-related potential that is found across task contexts (Dehaene et al., 1994; Holroyd et al., 1998; for review, see Holroyd and Coles, 2002). It has been proposed that activity in AACC may reflect the need for an adjustment in task performance (Ridderinkhof et al., 2004), either via altered stimulus processing (Danielmeier et al., 2011), and/or posterror slowing (King et al., 2010; Danielmeier and Ullsperger, 2011).

Reports of error-related blood oxygen level-dependent (BOLD) activity, however, have emerged that implicate several additional regions of interest. For example, numerous studies have demonstrated that frontal and parietal regions (e.g., dorsolateral prefrontal cortex, precuneus), as well as selected subcortical and cerebellar regions (Dosenbach et al., 2007; Carp et al., 2010; Wessel et al., 2012) show greater activity during errors than correct trials across many different tasks. Relatedly, it has been suggested that there are at least two cortical mechanisms (frontal 
Table 1. Twelve tasks used in the meta-analysis

\begin{tabular}{|c|c|c|c|c|c|c|c|c|c|c|c|c|}
\hline $\begin{array}{l}\text { Task } \\
\text { condition }\end{array}$ & $\begin{array}{l}1 \\
\text { Living/ } \\
\text { nonliving }\end{array}$ & $\begin{array}{l}2 \\
\text { Recognition } \\
\text { memory }\end{array}$ & $\begin{array}{l}3^{*} \\
\text { Semantic } \\
\text { judgment }\end{array}$ & $\begin{array}{l}4^{*} \\
\text { Physical } \\
\text { judgment }\end{array}$ & $\begin{array}{l}5^{*} \\
\text { Abstract/ } \\
\text { concrete }\end{array}$ & $\begin{array}{l}6^{*} \\
\text { Rhyme/ } \\
\text { no rhyme }\end{array}$ & $\begin{array}{l}7^{*} \\
\text { Noun/ } \\
\text { verb }\end{array}$ & $\begin{array}{l}8^{*} \\
\text { Mental } \\
\text { rotation }\end{array}$ & $\begin{array}{l}9 \\
\text { Source } \\
\text { memory }\end{array}$ & $\begin{array}{l}10 \\
\text { eCtva }\end{array}$ & $\begin{array}{l}11 \\
\text { Auditory: } \\
\text { abstract/ } \\
\text { concrete }\end{array}$ & $\begin{array}{l}12 \\
\text { Word } \\
\text { Generation }\end{array}$ \\
\hline $\begin{array}{l}\text { Original } \\
\text { publication }\end{array}$ & $\begin{array}{c}\text { Church, et al. } \\
\text { (2009) }\end{array}$ & $\mathrm{N} / \mathrm{A}$ & N/A & N/A & $\begin{array}{c}\text { Neta, et al. } \\
\text { (2014) }\end{array}$ & $\begin{array}{c}\text { Neta, et al. } \\
\text { (2014) }\end{array}$ & $\begin{array}{l}\text { Dubis, et al. } \\
\text { (2014) }\end{array}$ & $\begin{array}{c}\text { Dubis, et al. } \\
\text { (2014) }\end{array}$ & $\begin{array}{l}\text { Donaldson, } \\
\text { et al. } \\
(2010)\end{array}$ & $\mathrm{N} / \mathrm{A}$ & N/A & $\mathrm{N} / \mathrm{A}$ \\
\hline Stimuli & Images & Words & Nouns & Nouns & Nouns & Words & Nouns/verbs & $\begin{array}{r}\text { Tetris-like } \\
\text { shapes }\end{array}$ & Words & Words & Nouns & Nouns \\
\hline $\begin{array}{l}\text { Input } \\
\text { modality }\end{array}$ & Visual & Visual & Visual & Visual & Auditory & Visual & Visual & Visual & Visual & $\begin{array}{c}\text { Auditory/ } \\
\text { visual }\end{array}$ & Auditory & Visual \\
\hline $\begin{array}{l}\text { Output } \\
\text { modality }\end{array}$ & Button & Button & Button & Button & Button & Button & Button & Button & Button & $\begin{array}{l}\text { Button/ } \\
\text { speech }\end{array}$ & Button & Speech \\
\hline $\begin{array}{l}\text { No. of } \\
\text { subjects }\end{array}$ & 24 (12 male) & 20 (10 male) & 19 (9 male) & 14 (5 male) & 34 (18 male) & 34 (18 male) & 30 (16 male) & 30 (16 male) & 26 (14 male) & 30 (14 male) & 24 (12 male) & 21 (10 male) \\
\hline $\operatorname{TR}(s)$ & 2.5 & 2.36 & 2.5 & 2.5 & 2.5 & 2.5 & 2.5 & 2.5 & 2.5 & 2.5 & 2.5 & 2.5 \\
\hline No. of trials & 152 & 480 & 200 & 200 & 250 & 250 & 180 & 180 & 300 & 400 & 192 & 125 \\
\hline $\begin{array}{l}\text { Trial event } \\
\text { timing } \\
(\%)\end{array}$ & $\begin{array}{c}37,35,28 \\
0,0\end{array}$ & $\begin{array}{c}51,17,16 \\
14,2\end{array}$ & $\begin{array}{c}58,27,11 \\
4,0\end{array}$ & $\begin{array}{c}58,27,11 \\
4,0\end{array}$ & $\begin{array}{c}30,41,25 \\
3,0\end{array}$ & $\begin{array}{c}30,41,25 \\
3,0\end{array}$ & $\begin{array}{c}35,32,33 \\
0,0\end{array}$ & $\begin{array}{c}35,32,33 \\
0,0\end{array}$ & $\begin{array}{c}75,18,5 \\
2,0\end{array}$ & $\begin{array}{c}31,34,32 \\
1,1\end{array}$ & $\begin{array}{c}35,29,35 \\
0,0\end{array}$ & $\begin{array}{c}0,34,33 \\
33,0\end{array}$ \\
\hline $\begin{array}{l}\text { Stimulus } \\
\qquad \begin{array}{l}\text { ITI (s) } \\
\text { mean, } \\
\text { (range) }\end{array}\end{array}$ & $3.5(1.2-6.2)$ & $3.0(0.9-7.9)$ & $3.5(2.0-9.5)$ & $3.5(2.0-9.5)$ & $4.0(1.8-6.8)$ & $2.7(0.5-5.5)$ & $4.5(2.0-7.0)$ & $4.5(2.0-7.0)$ & $2.4(1.7-6.7)$ & $4.2(1.8-6.8)$ & $4.3(1.8-6.8)$ & $7.2(4.7-9.7)$ \\
\hline $\begin{array}{l}\text { Accuracy } \\
\text { rate }\end{array}$ & 98 & 85 & 93 & 99 & 89 & 90 & 94 & 75 & 85 & 99 & 92 & 88 \\
\hline $\begin{array}{l}\text { Stimulus } \\
\text { duration } \\
\text { (ms) }\end{array}$ & 1300 & 1500 & 500 & 500 & Varied & 2000 & 500 & 500 & 750 & Varied/700 & Varied & 300 \\
\hline Scanner & $1.5 \mathrm{~T}$ & $1.5 \mathrm{~T}$ & $1.5 \mathrm{~T}$ & $1.5 \mathrm{~T}$ & $3 \mathrm{~T}$ & $3 \mathrm{~T}$ & $3 \mathrm{~T}$ & $3 \mathrm{~T}$ & $1.5 \mathrm{~T}$ & $1.5 \mathrm{~T}$ & $1.5 \mathrm{~T}$ & $1.5 \mathrm{~T}$ \\
\hline Design type & $\begin{array}{l}\text { Mixed block/ } \\
\text { event- } \\
\text { related }\end{array}$ & $\begin{array}{l}\text { Event- } \\
\text { related }\end{array}$ & $\begin{array}{l}\text { Mixed block/ } \\
\text { event- } \\
\text { related }\end{array}$ & $\begin{array}{l}\text { Mixed block/ } \\
\text { event- } \\
\text { related }\end{array}$ & $\begin{array}{l}\text { Mixed block/ } \\
\text { event- } \\
\text { related }\end{array}$ & $\begin{array}{l}\text { Mixed block/ } \\
\text { event- } \\
\text { related }\end{array}$ & $\begin{array}{l}\text { Mixed block/ } \\
\text { event- } \\
\text { related }\end{array}$ & $\begin{array}{l}\text { Mixed block/ } \\
\text { event- } \\
\text { related }\end{array}$ & $\begin{array}{l}\text { Event- } \\
\text { related }\end{array}$ & $\begin{array}{l}\text { Mixed block/ } \\
\text { event- } \\
\text { related }\end{array}$ & $\begin{array}{l}\text { Mixed block/ } \\
\text { event- } \\
\text { related }\end{array}$ & $\begin{array}{l}\text { Event- } \\
\text { related }\end{array}$ \\
\hline
\end{tabular}

*These tasks represent pairs of studies that were run on the same set of participants: 3 and 4,5 and 6,7 and 8 .

and parieto-occipital) for errors, that may be modulated by task demands (van Driel et al., 2012).

In the broader context of task control, our laboratory has suggested a dual-network hypothesis, whereby two distinct control networks (i.e., frontoparietal and cingulo-opercular) independently, and in parallel, receive performance feedback signals (Dosenbach et al., 2007). Consistent with this model, we expect to find error-related signals in both of these networks, and perhaps other control-related networks (Petersen and Posner, 2012). Further, we suspect that there will be a division of labor in processing errors, where different regions may play different roles, temporally and functionally.

The goal of the present work was to define and characterize neural responses to errors. First, we used a meta-analytic approach to identify regions throughout the brain that show differential BOLD activity between error and correct responses, spanning task contexts. Second, we examined the time courses for the error-related (and correct) responses in these regions to determine their response profile on a trialwise basis. Finally, we demonstrated that resting-state functional connectivity (RSFC) informs these task-based findings, confirming distinction by both functional network affiliation and time course profile.

\section{Materials and Methods}

Task conditions included in the cross-studies analysis

Data from a total of nine different mixed block/event-related and three additional event-related experiments, conducted on 228 human subjects (115 male) at Washington University were included in this analysis (Table 1). All of the subjects were healthy adults between 18 and 35 years of age. Written informed consent was obtained from each participant before the session, and all were compensated for their participation through monetary payment. All procedures were approved by the Washington University Committee for the Protection of Human Subjects. The only criteria used for selecting tasks to include in the meta-analysis was that they resulted in enough error trials to allow us to model responses to error (omission and commission) and correct trials separately. Importantly, we tried to ensure that a broad set of task demands were represented by including tasks containing images, words, and word pairs. To ensure some degree of variability in output-specific responses, we used two tasks in which subjects indicated their responses by speaking aloud instead of pressing a button. Similarly, for input-specific responses, two of the tasks used only auditory stimuli, and an additional task used a combination of auditory and visual stimuli. Subjects were also asked to perform a variety of intermediate operations, such as different semantic or phonological classifications, visual classifications, memory tasks, naming, visual search, and reading. No error feedback was provided to the subjects in any of these studies. Note: task no. 10 was an eCtva task, which is an executive control of Bundensen's theory of visual attention, which deals with the selection between tasks in dual-task situations (Logan and Gordon, 2001).

\section{Image acquisitions}

All images were acquired in adherence to the same standard protocol. For the first set of tasks (i.e., Living/Nonliving no. 1; Recognition Memory no. 2; Semantic Judgment no. 3; Physical Judgment no. 4; Source Memory no. 9; eCtva no. 10; Auditory Abstract/Concrete no. 11; and Word Generation no. 12), images were obtained with a Siemens MAGNETOM Vision 1.5 tesla scanner. A T1-weighted sagittal MPRAGE structural image was obtained $(\mathrm{TE}=4 \mathrm{~ms}$; MR frame $=9.7 \mathrm{~ms}$; TI $=300 \mathrm{~ms}$; flip angle $=12^{\circ}$; 128 slices with $1.25 \times 1 \times 1 \mathrm{~mm}$ voxels; Mugler and Brooke- 
A
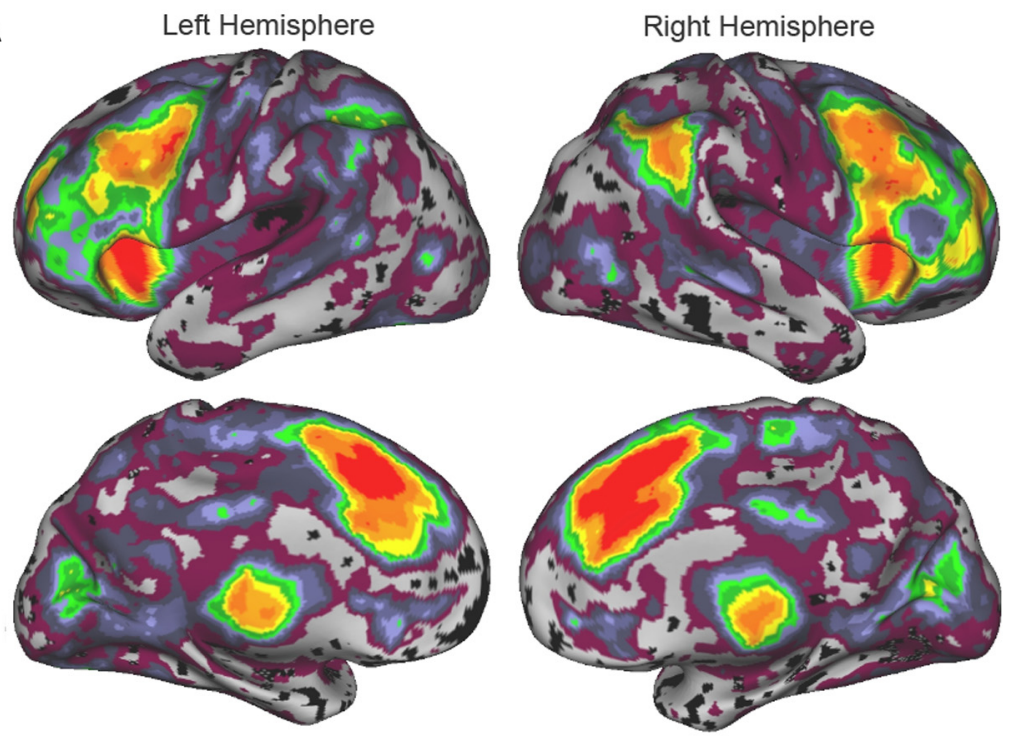

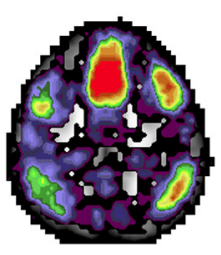

$Z=45$

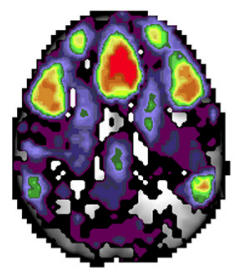

$Z=\mathbf{3 0}$

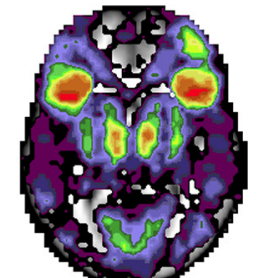

$Z=6$

atatse

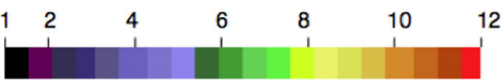

B

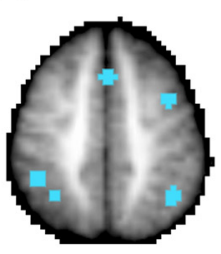

$Z=45$

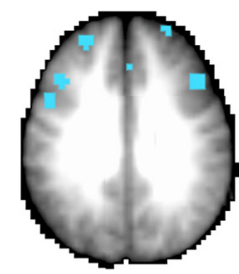

$Z=\mathbf{3 0}$

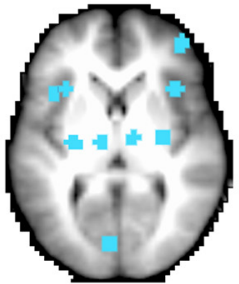

$Z=6$

Figure 1. A, A consensus map of regions that showed differential activity between error and correct trials, across 12 tasks. This map is represented on the surface, and below that, on several slices of the volume. $\boldsymbol{B}$, The consensus image was used to define ROls that showed differential activity to errors and correct trials in at least seven tasks (41 ROls), shown on several slices of the volume.

man, 1990). Functional imaging was performed using a BOLD contrastsensitive asymmetric spin-echo echoplanar sequence $\left(\mathrm{T} 2^{\star}\right.$ evolution time $=50 \mathrm{~ms}$; flip angle $=90^{\circ}$, in-plane resolution $\left.3.75 \times 3.75 \mathrm{~mm}\right)$. Whole-brain EPI acquisitions (MR frames) of 16 contiguous, $8-\mathrm{mm}$ thick axial slices were obtained parallel to the anterior-posterior commissure plane.

For the remaining tasks, (i.e., Abstract/Concrete no. 5; Rhyme/No Rhyme no. 6; Noun/Verb no. 7, Mental Rotation no. 8) data were acquired on a Siemens 3T TIM Trio scanner with a 12-channel Siemens Matrix head coil. A T1-weighted MPRAGE structural image was obtained (slice time echo $=3.08 \mathrm{~ms}, \mathrm{TR}=2.4 \mathrm{~s}, \mathrm{TI}=1000 \mathrm{~ms}$, flip angle $=$ $8^{\circ}, 176$ slices, $1 \times 1 \times 1 \mathrm{~mm}$ voxels). All functional runs were acquired parallel to the anterior-posterior commissure plane using a BOLD contrast-sensitive asymmetric spin-echo echoplanar sequence $(\mathrm{TE}=27$ $\mathrm{ms}$; volume $\mathrm{TR}=2.5 \mathrm{~s}$, flip angle $=90^{\circ}$, in-plane resolution $=4 \times 4$ $\mathrm{mm})$. Whole-brain coverage was obtained with 32 contiguous interleaved $4 \mathrm{~mm}$ axial slices. An auto-align pulse sequence protocol provided in the Siemens software was used to align the acquisition slices to the anterior and posterior commissure plane and centered on the brain. A

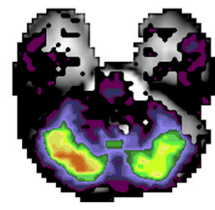

$Z=-\mathbf{3 0}$

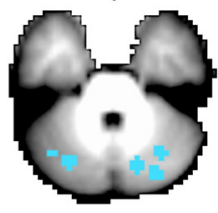

$Z=-\mathbf{3 0}$
T2-weighted turbo spin echo structural image $(\mathrm{TE}=84 \mathrm{~ms}, \mathrm{TR}=6.8 \mathrm{~s}, 32$ slices with $1 \times 1 \times$ $4 \mathrm{~mm}$ voxels) was also obtained in the same anatomical plane as the BOLD images to improve alignment to the atlas.

For both sets of tasks, each subject was fitted with a thermoplastic mask fastened to the head coil using custom-made clamps to help stabilize head position. Additionally, the first four frames of the BOLD time series were skipped to assure steady-state magnetization.

\section{Imaging analysis}

Preprocessing. The same preprocessing stream was used for all the studies included in the analysis. Initial data processing to remove noise and artifacts was performed using a series of automated steps, including (1) temporal realignment using sinc interpolation of all slices to the temporal midpoint of the first slice, accounting for differences in the acquisition time of each individual slice, (2) correction for movement within and across BOLD runs using a rigid-body rotation and translation algorithm (Snyder, 1996), and (3) whole brain intensity normalization for each functional run by multiplying the intensity value of all of the voxels by a single factor to achieve a modal value of 1000 across all of the image voxels to allow comparisons across subjects (Ojemann et al., 1997). Individual subject data were not smoothed; smoothing was performed only on group data. Functional data were then resampled into $3 \mathrm{~mm}$ isotropic voxels and transformed into stereotaxic atlas space (Talairach and Tournoux, 1988). Atlas registration involved aligning each subject's T1-weighted image to a custom atlas-transformed (Lancaster et al., 1995) target T1-weighted template using a series of affine transforms (Michelon et al., 2003; Fox et al., 2005).

Analysis using the GLM: unassumed shape. Time course modeling was performed using in-house software written in IDL (Research Systems). A general linear model (GLM) was used to model the BOLD response in each subject for each of the events in each of the tasks. Included in the model were error trials (combining omission and commission errors) and correct trials (combining all conditions within an experiment). We also included in the model baseline and linear trend activity across each BOLD run. Additionally, for the studies with a mixed-block/event-related design (Table 1), we modeled the onset and offset of each block of trials, as well as the block as a constant change (i.e., boxcar) in MR signal. For the initial unassumed shape set of analyses, the shape of the BOLD response for each of the transient signals (error, correct, onset, and offset) was not included in the GLM but rather estimated from 10 time points included in the design matrix for the GLM (Miezin et al., 2000). These 10 time points represent the magnitude of the error and correct response waveforms at 10 successive frames (TRs). The first time point corresponds to the time at which the stimulus is presented and all are obtained from the GLM estimates. There is one time point per TR so for an experiment where TR $=2.5 \mathrm{~s}$, the waveforms are sampled for a total period of $25 \mathrm{~s}$.

An accuracy $\times$ time repeated-measures ANOVA of fMRI BOLD responses was performed for each task. This analysis yielded a statistical map highlighting brain regions in which the time courses for error trials were significantly different from the time courses for correct trials, over 10 time points. In other words, we identified regions that showed differ- 
Table 2. The list of regions that showed differential activity between errors and correct trials on at least seven of the tasks, organized by response profile and functional network membership

\begin{tabular}{|c|c|c|c|c|c|}
\hline \multirow[b]{2}{*}{ ROI } & \multicolumn{3}{|c|}{ Coordinates } & \multirow[b]{2}{*}{ Response profile } & \multirow[b]{2}{*}{ Network assignment } \\
\hline & $x$ & $y$ & $z$ & & \\
\hline R thalamus & 9 & -15 & 9 & Fast & Thalamus \\
\hline R thalamus & 10 & -3 & 15 & Fast & Thalamus \\
\hline L thalamus & -9 & -16 & 9 & Fast & Thalamus \\
\hline R lingual & 13 & -68 & 11 & Fast & Visual \\
\hline L calcarine & -5 & -78 & 7 & Fast & Visual \\
\hline L anterior lingual & -17 & -60 & -1 & Fast & Visual \\
\hline L anterior insula/frontal operculum & -31 & 15 & 12 & Fast & Cingulo-opercular \\
\hline L anterior insula/frontal operculum (lateral) & -39 & 13 & 5 & Fast & Cingulo-opercular \\
\hline R anterior insula/frontal operculum & 34 & 17 & 8 & Fast & Cingulo-opercular \\
\hline R anterior insula/frontal operculum (lateral) & 45 & 17 & 13 & Fast & Cingulo-opercular \\
\hline Medial superior frontal & -2 & 6 & 51 & Fast & Cingulo-opercular \\
\hline Medial superior frontal (ventral) & -1 & 17 & 44 & Fast & Frontoparietal/Cingulo-opercular \\
\hline L anterior middle frontal & -42 & 25 & 24 & Fast & Frontoparietal \\
\hline R anterior middle frontal & 42 & 17 & 30 & Fast & Frontoparietal \\
\hline L middle frontal & -47 & 6 & 34 & Fast & Frontoparietal \\
\hline L Precentral & -38 & -2 & 37 & Fast & Frontoparietal \\
\hline L inferior parietal lobule & -42 & -45 & 41 & Fast & Frontoparietal \\
\hline L intraparietal sulcus & -33 & -56 & 40 & Fast & Frontoparietal \\
\hline L inferior frontal & -40 & 18 & 34 & Fast & Frontoparietal \\
\hline L anterior prefrontal (ventral) & -29 & 46 & 22 & Prolonged & Salience \\
\hline Dorsal anterior cingulate & 1 & 26 & 35 & Prolonged & Salience/Frontoparietal \\
\hline R anterior prefrontal & 24 & 49 & 28 & Prolonged & Salience \\
\hline L anterior prefrontal & -25 & 42 & 29 & Prolonged & Salience \\
\hline R supramarginal & 47 & -48 & 35 & Prolonged & Frontoparietal \\
\hline R posterior middle frontal & 36 & 3 & 42 & Prolonged & Frontoparietal \\
\hline R dorsolateral prefrontal & 37 & 12 & 38 & Prolonged & Frontoparietal \\
\hline R anterior middle frontal & 30 & 49 & 18 & Prolonged & Parietal \\
\hline R lateral parietal & 38 & -56 & 42 & Prolonged & Parietal \\
\hline R inferior frontal & 42 & 31 & 3 & Prolonged & Ventral attention \\
\hline L cerebellum & -27 & -66 & -31 & Prolonged & Cerebellum \\
\hline L cerebellum & -36 & -62 & -24 & Prolonged & Cerebellum \\
\hline L cerebellum & -37 & -54 & -37 & Prolonged & Cerebellum \\
\hline R cerebellum & 29 & -60 & -32 & Prolonged & Cerebellum \\
\hline R cerebellum & 25 & -73 & -32 & Prolonged & Cerebellum \\
\hline R cerebellum & 15 & -69 & -28 & Prolonged & Cerebellum \\
\hline R posterior putamen & 27 & -14 & 8 & Delayed & Subcortical \\
\hline R putamen & 25 & -5 & 1 & Delayed & Subcortical \\
\hline L posterior putamen & -27 & -18 & 8 & Delayed & Subcortical \\
\hline L putamen & -28 & -5 & 2 & Delayed & Subcortical \\
\hline R inferior frontal & 38 & 44 & 9 & NA & NA \\
\hline Posterior dorsal frontal & 0 & -28 & 58 & NA & NA \\
\hline
\end{tabular}

ential activity for error versus correct trials, over time, and not necessarily focusing on those that showed error $>$ correct activity. The resultant $f$ map was transformed to a Z-score map, thresholded at $z=2.5$, and then binarized such that all values above $z=2.5$ were given a value of 1 . This somewhat low threshold of $z=2.5$ was chosen to allow each task to contribute regions to the consensus map; at a higher threshold, some tasks showed almost no error-related activity. The binarized images for each task were then combined to form a consensus image that showed the number of tasks that had differential activity to errors (including both omissions and commissions) than correct trials (Fig. 1A). Brain surface visualizations were created using Caret software and the PALS surface atlas (Van Essen et al., 2001; Van Essen, 2005).

ROI definition. The consensus image was used to define regions-ofinterest (ROIs). In other words, because we aimed to identify errorrelated activity spanning multiple task contexts, we focused on regions that showed differential activity between error and correct trials in the majority of our tasks (i.e., more than half, or at least 7 tasks). Functional ROI volumes were defined by growing spheres ( $10 \mathrm{~mm}$ diameter) around peak voxels using algorithms developed by Abraham Snyder (Wheeler et al., 2006). This procedure resulted in 41 ROIs (Fig. 1B). Table 2 shows a list of the coordinates of each of these ROIs. Time courses were extracted separately for error and correct trials in each ROI in each task, and then averaged across all of the tasks.
Hierarchical cluster analysis. To identify regions with distinct response profiles (i.e., distinct time courses of error-related activity), we used a hierarchical clustering analysis (Cordes et al., 2002; Salvador et al., 2005; Dosenbach et al., 2007) to classify the time course profiles in the 41 ROIs. Two time courses, each consisting of 10 time points, were extracted from each ROI (one time course for errors, and a second for correct trials) for each task, and then averaged across all the tasks. The two time courses were concatenated, resulting in a $1 \times 20$ vector of time points for each ROI, the first 10 points representing responses in correct trials, the second 10 points representing responses in error trials. A $41 \times 20$ matrix containing each vector from the 41 predefined ROIs was then formed. In other words, the clustering analysis was conducted on the time course of activity for both error and correct trials.

From these values, a dendrogram (cluster tree) depicting region-byregion relationships was constructed. The method used to build the dendrogram was the commonly chosen unweighted paired group method with arithmetic mean (UPGMA; Handl et al., 2005), which is included in the Statistics and Bioinformatics Toolboxes available in MATLAB 7.2 (MathWorks). The UPGMA algorithm defines the distance between two clusters as the mean distance of all possible pairs of data points between the two clusters, and is thought to be the most unbiased of the major choices. To objectively cut the dendrogram into distinct clusters, we used an algorithm to report modularity for a structure that contains anywhere 
A
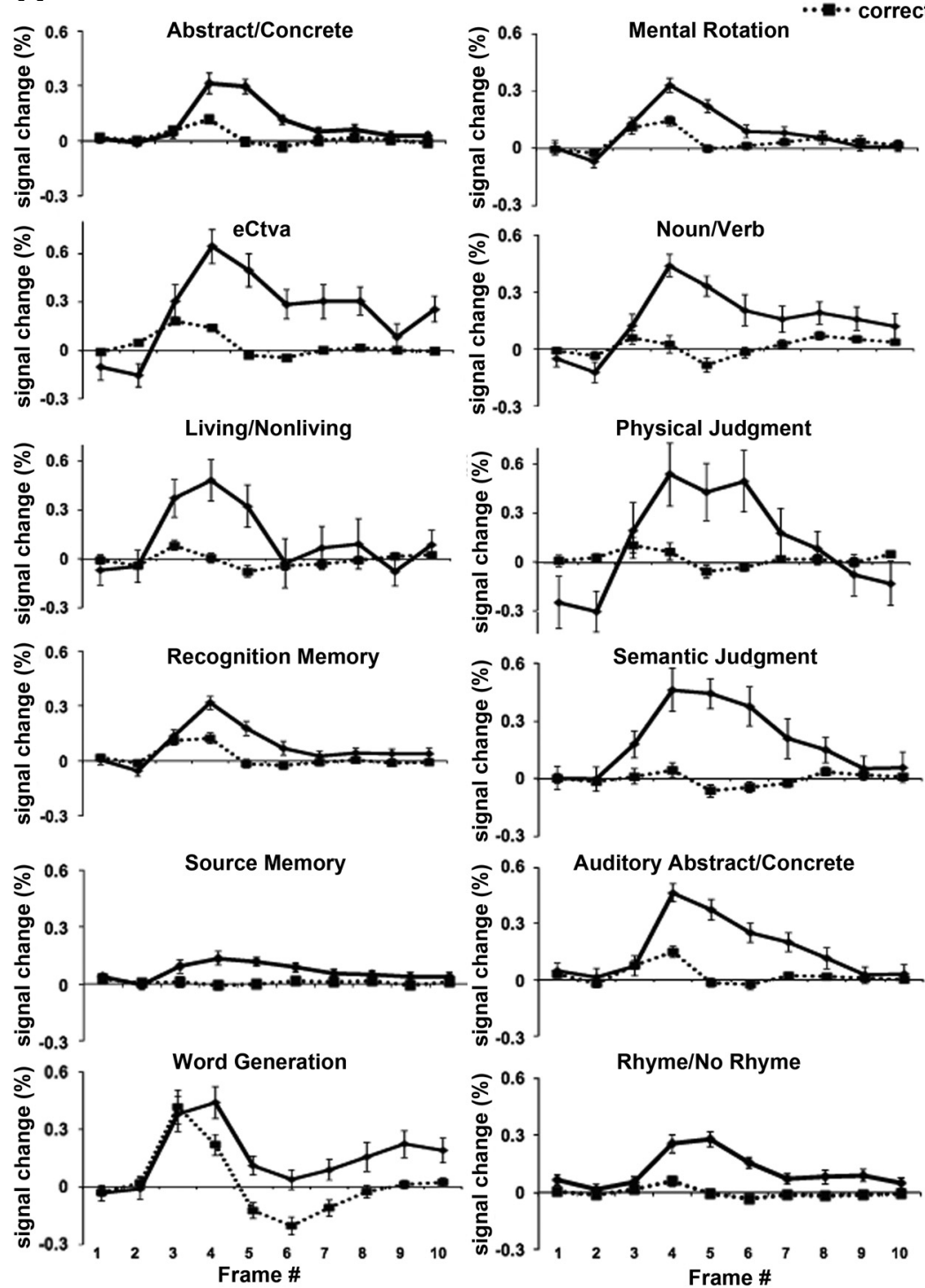

B

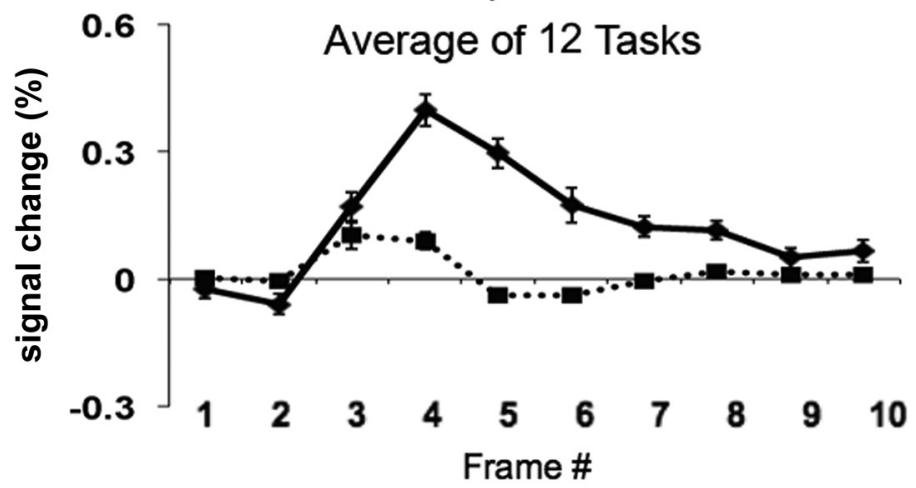

$\operatorname{dACC}(1,26,35)$

Figure 2. For each region (sample here in $\mathrm{dACC}$ ), we averaged separately the time course of activity for error and correct trials across the 12 tasks. $\boldsymbol{A}$, The time courses for each task. SE bars reflect variance across subjects within a task. $\boldsymbol{B}$, The time course for the average across all tasks. SE bars reflect variance across tasks.

from 1 to 10 total clusters (Newman, 2006), and we chose the structure that had the highest $Q$ coefficient (1.102), which included five clusters. Two of these clusters contained only one region each, but 39 of the 41 ROIs were split into three clusters. To corroborate this distinction based on time courses, we also ran an accuracy (error, correct) $\times$ time (10 frames) ANOVA where the three clusters served as a between region factor.

Analysis using the GLM: assumed shape. To contextualize our findings with those that might be derived using other methods, a second GLM analysis was performed in which the shape of the BOLD response was assumed to be a double gamma waveform. As pointed out in Cassidy and Solo (2012), this waveform is frequently used in FSL and SPM to model BOLD responses and consists of subtracting two gamma functions from each other to generate a resulting function with an undershoot. The parameter values used in our analysis are identical to those specified in that paper. Additionally, we included in our GLM design matrix a second term equal to the derivative of the double gamma waveform. This term will account for some of the time delay in the BOLD response relative to the assumed response. For both waveforms, the amplitude of the waveform is estimated but only the magnitude of the double-gamma waveform is used for the subsequent statistical tests. These same parameters were used for all tasks.

A repeated-measures statistical analysis of the estimated magnitude of the response for the correct trials versus the error trials was performed. All of the subsequent statistical procedures were identical to the procedures used for the unassumed shape GLM analysis.

Network analysis. We visualized the map of error-related activity within the borders of the predefined functional networks (Power et al., 2011) to determine whether the activity is constrained to a single network or whether it crosses network boundaries. Then, we included the ROIs in a network analysis to determine whether the clustering based on response profiles was reflected in functional correlations at rest (e.g., are regions of a particular profile more strongly correlated than those that cross profiles). It is worth noting here that restingstate functional connectivity is correlated with known structural (Greicius et al., 2009), and functional connectivity (Biswal et al., 1995; Shmuel and Leopold, 2008). In this analysis, we included only those ROIs that were placed into one of the three large clusters in the dendrogram (i.e., 39 of the 41 ROIs). Edges, or the connections between nodes, are defined based on RSFC from a separate set of 120 normal adults (Power et al., 2011 for information on data acquisition). This RSFC data underwent standard processing, including a "scrubbing" procedure to minimize motion-related effects (Power et al., 2012, 2013). To visualize the network structure, we used a standard technique called spring-embedding. Graphs were created by using the Kamada-Kawai spring-embedding algorithm implemented in the Social Network 
A

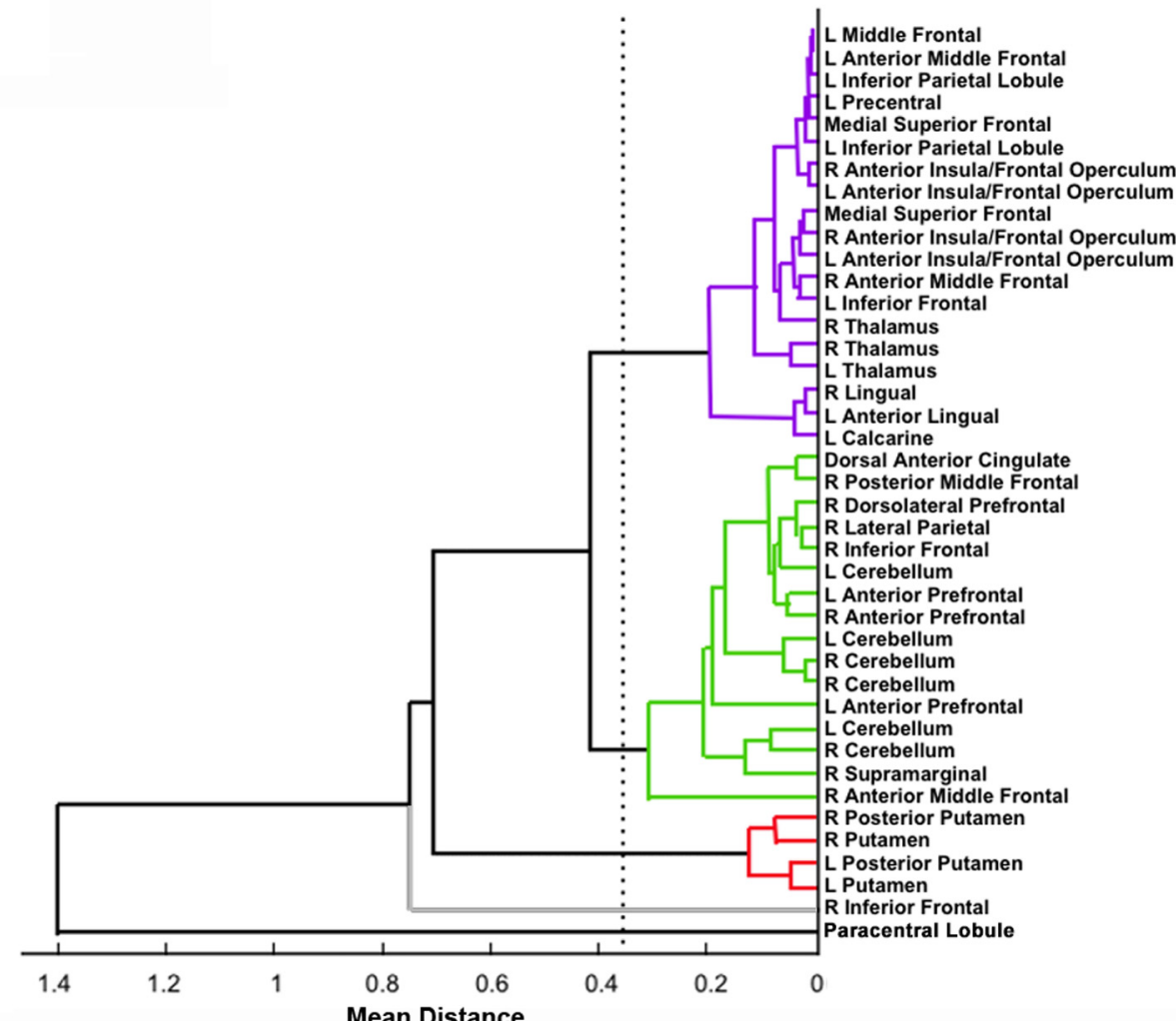

B
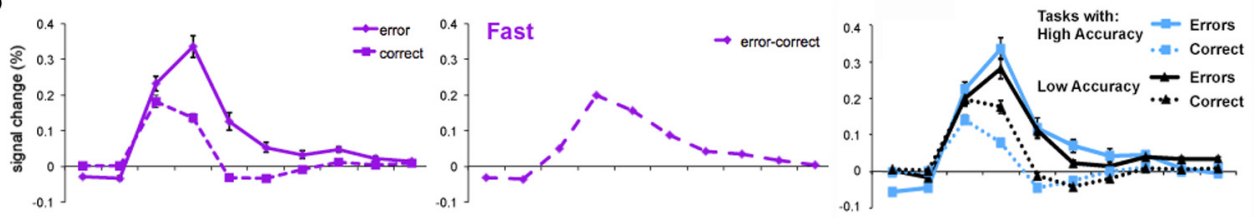

C
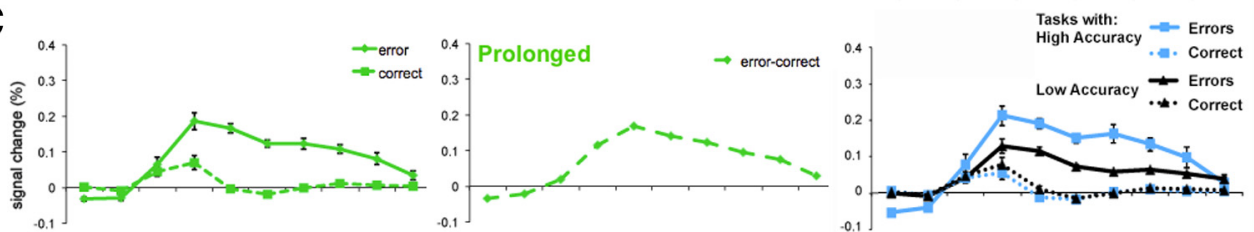

D
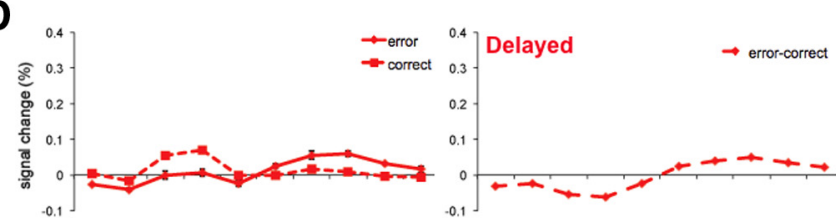

E
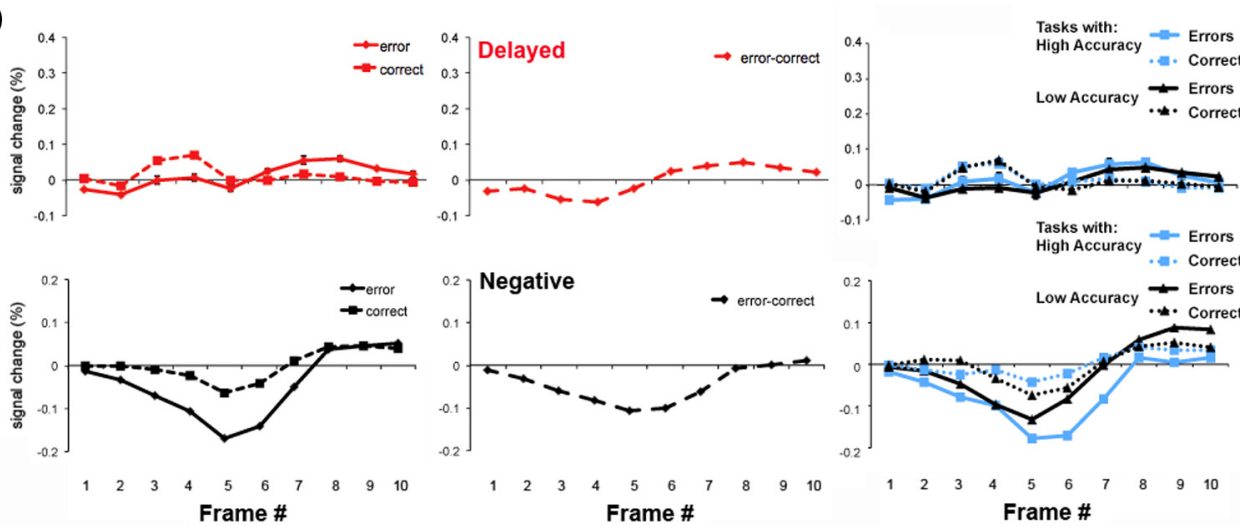

Figure 3. A, The dendrogram resulting from a hierarchical cluster analysis of the time courses averaged across all the tasks from 41 R0ls. The 39 regions represented in color were grouped into four distinct clusters represented in different colors, each with a unique response profile. The two ROls at the bottom did not fit well into any of the clusters, so they were removed from all further analyses. $\boldsymbol{B}-\boldsymbol{E}$, Time courses are averaged across the regions in each cluster and shown in two graphs, one that shows both error and correct time courses, and one that shows the difference (error minus correct). SE bars reflect variance across regions. Note: All SE bars have been plotted, but many of them are so small that they do not show up on this scale. $\boldsymbol{B}$, The top 19 ROIs showed a fast response profile, $(\boldsymbol{C})$ the next 16 ROls showed a prolonged response profile, and (D) the last four ROls showed a response on correct trials that was followed by a delayed response for error trials. $\boldsymbol{E}$, The region at the bottom (black) showed a negative profile. Although this region did not cluster with any of the other response profiles, we show its time course here as a comparison. 
Image Animator (SoNIA) software package (Bender-deMoll and McFarland, 2006). Specifically, nodes were given a fixed-repulsive force and placed randomly in a plane, and springs with force constants related to the pairwise correlation coefficients were placed between all nodes. This spring system was allowed to iteratively reposition nodes to reduce the energy of the spring system, resulting in a final low-energy state, where groups of nodes with high correlations are positioned near one another, and those with weak or no connections are placed more distantly.

\section{Results}

A large number of regions show error-related activity across a wide range of tasks

Based on a consensus image of accuracy $\times$ time effects across all 12 tasks, we identified brain regions in which the activity for error trials was significantly different from the activity for correct trials (Fig. 1A). Those regions that showed differential activity between errors and correct trials (however, not necessarily showing error $>$ correct activity) on at least seven of the 12 tasks were isolated as ROIs, yielding 41 ROIs distributed across cortical, subcortical, and cerebellar regions (Fig. 1B). Of the 41 ROIs, 37 showed greater activity for error than correct trials. Importantly, despite the previous focus on the dorsal anterior cingulate, anterior insula, inferior parietal lobule, and intraparietal sulcus in processing errors, these 41 ROIs were not isolated to these regions of cortex; rather, they were distributed across frontal, parietal, and occipital cortex, as well as subcortical and cerebellar regions (Table 2 shows a list of coordinates).

\section{There are three distinct error response profiles}

For each region, we averaged the respective time courses of activity for error and correct trials across the 12 tasks (Fig. 2 shows a sample in the dACC region; $A$ shows the time courses for each individual task and $B$ shows the average across tasks). In a hierarchical cluster analysis of this averaged activity, 39 of 41 ROIs were grouped into three distinct clusters (Fig. $3 A$ ), each with a unique response profile. There were two ROIs that did not fit well into any of the clusters (one in paracentral lobule that showed a deactivation (Fig. $3 E$ ), and the other showed a profile that did not resemble a HRF), so they were removed from all further analyses.

To distinguish the response profiles corresponding to each of the three clusters, we averaged the concatenated time courses (i.e., 20 time points, 10 per time course for error and correct responses) across the regions in each cluster. The first cluster, shown in purple, comprised 19 ROIs. The average time course across the 19 ROIs showed a "fast" response profile to errors, where the time course showed a fast return to (near) baseline within three frames of reaching its peak (i.e., fast regions; Fig. 3B). The next cluster, shown in green, included 16 ROIs that showed a prolonged response profile for errors, meaning there was a prolonged return to baseline, over the course of twice as many frames as the fast profile (i.e., prolonged regions; Fig. 3C). The last cluster, shown in red, comprised four ROIs that showed a response to error trials with a delayed onset, which showed a much earlier significant response on correct trials (i.e., delayed regions; Fig. 3D). The location of each of the 39 ROIs, as well as the one ROI that showed a negative time course, is represented on the surface of the brain in Figure 4. Finally, we corroborate this response profile distinction by showing that there was a significant accuracy $\times$ time $\times$ profile interaction $\left(F_{(9,29)}=9.89, p<0.001\right)$, such that the profiles showed significantly different error-related responses beginning at time point 3 (i.e., fast is significantly different from the other two), and all of the profiles were significantly different from each other starting at time point 4 , with the prolonged profile continuing to show a significantly different response through time point 9.
Due to the variability in accuracy across the 12 tasks, one might think that only tasks with a greater error frequency show these effects. To address this, we conducted a median split analysis where we separated the 12 tasks into two groups: those with the highest accuracy (tasks 1, 3, 4, 7, 10, and 11) and those with the lowest accuracy (tasks 2, 5, 6, 8, 9, and 12), and compared the time courses in each group. We ran an accuracy (error, correct) $\times$ time $(10$ frames $) \times$ profile (fast, prolonged, delayed) $\times$ task group (high accuracy, low accuracy) ANOVA. There was no significant effect of task group $\left(F_{(1,72)}=0.41, p>0.5\right)$, and no significant accuracy $\times$ profile $\times$ task group interaction $\left(F_{(2,72)}=2.80, p>0.05\right)$. However, because this interaction was near trend, we examined post hocs and found an effect for correct trials in fast regions $(p<0.001)$, where activity was greater for low than high accuracy tasks (i.e., tasks with more errors showed a greater response on correct trials than tasks with fewer errors; Fig. 3B, right, dashed black line is greater than dashed blue line). There was also a significant effect for error trials in prolonged regions $(p<0.005)$, where activity was greater for high than low accuracy tasks (i.e., tasks with fewer errors showed a greater response on error trials than tasks with more errors; Fig. $3 C$, right, solid blue line is greater than solid black).

Finally, we reran the accuracy $\times$ time $\times$ profile ANOVA that corroborated the response profile distinction for each task group separately. All main effects and interactions were significant ( $p \leq$ $.001)$ in each task group.

\section{An analysis that assumes a hemodynamic response function results in only a small portion of the regions defined without assuming a shape}

The analyses discussed above did not assume a shape in the linear model for the BOLD response. We ran an additional analysis assuming a canonical hemodynamic response shape with derivatives and identified only 11 ROIs as related to errors (Table 3 ). Almost all of these ROIs (10 of 11) were within $10 \mathrm{~mm}$ of one of our original 41 ROIs (Table 4 shows the distance between the unassumed and assumed ROIs up to a $20 \mathrm{~mm}$ cutoff). Interestingly, 8 of 10 ROIs were closest to a region that showed a fast response profile (which is most similar to the canonical response shape), and only two ROIs (nos. 8 and 9) were closest to a region showing a prolonged profile; ROI no. 4 is closest to a fast region in the original set. None were within even $20 \mathrm{~mm}$ of a region that showed a delayed profile. In fact, the delayed regions, which showed substantially different response onset times for correct versus error trials, appeared to show a correct $>$ error response when modeling an assumed canonical shape.

The consensus map of regions that showed differential activity between error and correct trials on at least seven tasks is shown for both the models with an unassumed and assumed shape in Figure $5 \mathrm{~A}$. The figure shows that there was greater consensus across tasks in the error-related activity when an unassumed shape was used as opposed to when an assumed BOLD shape was used (i.e., none of the regions reached a consensus of 12 tasks for the assumed shape). To quantify the difference between the unassumed and assumed maps, we ran a fixed effects analysis of the unassumed shape across 12 tasks, and the assumed shape across 12 tasks, and then made a difference map (i.e., unassumed-assumed), as shown in Figure 5B.

\section{Resting-state functional connectivity informs task- based findings}

Figure 6 shows the same consensus map that we showed in Figure $1 A$, but only showing activity from more than half (at least 7) of the tasks. The overlaid boundaries demonstrate the functional 
networks of the brain, as defined by resting-state data (Fig. $6 \mathrm{~B}$ shows the map of these functional networks that was originally presented by Power et al., 2011). This map shows that error-related activity is not restricted to one, but appears to span a handful of different, mostly control, networks. Further, errorrelated activity most often does not fill any particular network, but rather is restricted to a specific subset of regions within each network. Previous studies have shown that resting state networks have overlapped with task-based distinctions, which motivated a resting state network distinction among the task-based errorrelated regions found here. A network analysis, using RSFC data and a standard network science technique called springembedding (see Materials and Methods), was used to determine whether the clustering based on response profiles was reflected in functional correlations at rest (e.g., are regions of a particular profile more strongly correlated than those that cross profiles?), as well as their relations to large-scale networks defined by Power et al. (2011).

A spring-embedded graph of errorrelated regions (Fig. 7A), is shown where nodes are colored based on response profile (as in Fig. 3). The spring-embedding reveals that the nodes that belong to the same response profile are positioned near one another (Fig. 7A). This organization provides support for the segregation of the regions based on response profile by showing that those regions, grouped together during task performance, are also grouped at rest.

Several additional striking patterns are apparent. First, none of the "delayed" nodes are directly connected to any of the "prolonged" nodes. Rather, the fast nodes appear to serve as links that connect the nodes of the other, more extended profiles (Fig. 7C). Second, and relatedly, none of the subcortical nodes are directly connected to any of the cerebellar nodes (Fig. 7A). Rather, the cortical nodes appear to serve as links that connect the subcortical and cerebellar nodes. Further, the prolonged nodes are represented in both cortex and cerebellum, but not other subcortical areas, whereas fast nodes are represented in both cortical and subcortical areas, but not the cerebellum.

The same graph, coded by functional networks (Fig. 7B; see color key) shows the same spring system, where nodes are colored based on functional network. First, it is evident that, although a great number of the error regions are represented in the cinguloopercular (purple) and frontoparietal (yellow) control systems, as was predicted based on the dual-network hypothesis (Dosenbach et al., 2008), there are also a variety of regions in other functional networks. Further, consistent with previous work (Power et al., 2011), the spring-embedding reveals that the nodes that belong to the same functional network are positioned near one another. Two of the nodes were positioned on a border between two different networks, and so those nodes were assigned two network colors (one is purple and yellow, the other is black and yellow). Interestingly, those nodes are positioned in the spring system in between their two corresponding networks.
Table 3. The list of regions that showed differential activity between errors and correct trials on at least seven of the tasks, using an assumed shape

\begin{tabular}{llrrr}
\hline & & \multicolumn{3}{l}{ Coordinates } \\
\cline { 3 - 5 } R0I no. & ROl location & $x$ & $y$ & $z$ \\
\hline 1 & L anterior insula/frontal operculum & -35 & 18 & 8 \\
2 & R anterior insula/frontal operculum & 35 & 23 & 4 \\
3 & L medial superior frontal (dorsal) & -6 & 11 & 51 \\
4 & R anterior insula/frontal operculum (lateral) & 46 & 22 & 3 \\
5 & R medial superior frontal (middle) & 6 & 25 & 36 \\
6 & R medial superior frontal (dorsal) & 6 & 18 & 44 \\
7 & L medial superior frontal (middle) & -6 & 21 & 42 \\
8 & L medial superior frontal (ventral) & -5 & 30 & 32 \\
9 & R dorsolateral prefrontal & 42 & 7 & 40 \\
10 & L dorsolateral prefrontal & -45 & 14 & 29 \\
11 & Caudate & -12 & 7 & 8 \\
\hline
\end{tabular}

Figure $7 C$ shows the graph colored by network, with circles around the regions of a particular profile (i.e., prolonged regions circled in green, fast regions circled in purple, and delayed regions circled in red), which should facilitate a comparison between the spring system colored by profile (Fig. $7 A$ ) and the one colored by network (Fig. 7B). Several patterns emerge here. First, with the exception of the frontoparietal network, each network shows its own distinct response profile (e.g., cingulo-opercular and visual nodes showed a fast profile, whereas cerebellum and salience nodes showed a prolonged profile). In contrast, some of the frontoparietal nodes showed a prolonged profile (all in the right hemisphere), whereas others showed a fast profile (all but one in the left hemisphere).

Second, the prolonged and fast profile groups are comprised of multiple functional networks [Fig. $7 A$, prolonged regions (green) are found in the cerebellum, the salience, ventral attention, frontoparietal and parietal networks, whereas fast regions 
Table 4. Comparison of our 41 ROIs (without assuming a response shape) with the 11 ROIs identified using an assumed shape

\begin{tabular}{|c|c|c|c|c|c|}
\hline \multicolumn{3}{|c|}{ Unassumed regions } & \multirow{2}{*}{$\begin{array}{l}\text { Response } \\
\text { profile }\end{array}$} & \multirow{2}{*}{$\begin{array}{l}\text { Nearest assumed } \\
\text { shape ROI no. }\end{array}$} & \multirow[b]{2}{*}{ Distance $(\mathrm{mm})$} \\
\hline$x$ & $y$ & $Z$ & & & \\
\hline 9 & -15 & 9 & Fast & & \\
\hline 10 & -3 & 15 & Fast & & \\
\hline-9 & -16 & 9 & Fast & & \\
\hline 13 & -68 & 11 & Fast & & \\
\hline-5 & -78 & 7 & Fast & & \\
\hline-17 & -60 & -1 & Fast & & \\
\hline-31 & 15 & 12 & Fast & 1 & 3.2 \\
\hline-39 & 13 & 5 & Fast & 1 & 8.8 \\
\hline 34 & 17 & 8 & Fast & 2 & 4.7 \\
\hline 45 & 17 & 13 & Fast & 4 & 4.4 \\
\hline-2 & 6 & 51 & Fast & 3 & 6.4 \\
\hline-1 & 17 & 44 & Fast & $5,6,7$ & $7.9,7.9,7.7$ \\
\hline-42 & 25 & 22 & Fast & 10 & 17.0 \\
\hline 42 & 17 & 30 & Fast & & \\
\hline-47 & 6 & 34 & Fast & 10 & 5.8 \\
\hline-38 & -2 & 37 & Fast & 10 & 14.0 \\
\hline-42 & -45 & 41 & Fast & & \\
\hline-33 & -56 & 40 & Fast & & \\
\hline-40 & 18 & 34 & Fast & 10 & 9.9 \\
\hline-29 & 46 & 22 & Prolonged & & \\
\hline 1 & 26 & 35 & Prolonged & 8 & 8.2 \\
\hline 24 & 49 & 28 & Prolonged & & \\
\hline-25 & 42 & 29 & Prolonged & & \\
\hline 47 & -48 & 35 & Prolonged & & \\
\hline 36 & 3 & 42 & Prolonged & 9 & 2.5 \\
\hline 30 & 49 & 18 & Prolonged & & \\
\hline 37 & 12 & 38 & Prolonged & 9 & 11.8 \\
\hline 38 & -56 & 42 & Prolonged & & \\
\hline 42 & 31 & 3 & Prolonged & 4 & 14.4 \\
\hline-27 & -66 & -31 & Prolonged & & \\
\hline-36 & -62 & -24 & Prolonged & & \\
\hline-37 & 54 & -37 & Prolonged & & \\
\hline 29 & -60 & -32 & Prolonged & & \\
\hline 25 & -73 & -32 & Prolonged & & \\
\hline 15 & -69 & -28 & Prolonged & & \\
\hline 27 & -14 & 8 & Delayed & & \\
\hline 25 & -5 & -1 & Delayed & & \\
\hline-27 & -18 & 8 & Delayed & & \\
\hline-28 & -5 & 2 & Delayed & & \\
\hline 38 & 44 & 9 & NA & & \\
\hline 0 & -28 & 58 & NA & & \\
\hline
\end{tabular}

(purple) are found in the thalamus, and the cingulo-opercular, frontoparietal, and visual networks]. In contrast, the delayed profile is found in four ROIs, all of which are in the basal ganglia.

\section{Discussion}

To examine the organization of error-related responses in healthy young adults, we conducted a meta-analysis of 12 different fMRI tasks, spanning various categories of inputs, sensory modalities, and outputs. This meta-analysis allowed us to identify brain regions responding to errors across many task contexts, and examine these responses in terms of their timescale and network membership. Here, we summarize our main findings.

\section{Error-related activity is spatially distributed}

The findings reported here demonstrate that a substantial number of brain regions respond differentially when errors occur. In addition to the widely recognized role of the dACC (Dehaene et al., 1994; Holroyd et al., 2004; Ridderinkhof et al., 2004), we found numerous error-related regions in frontal and parietal cortex, as well as subcortical and cerebellar regions. Although previous work (Hester et al., 2004; Tunik et al., 2005; Dosenbach et al.,
2006; Nelson et al., 2010; Ullsperger et al., 2010), has suggested that error-related activity occurs in regions beyond the dACC, we believe that the current presentation represents a relatively comprehensive inventory of error-related regions.

In particular, consistent with the dual-network hypothesis (Dosenbach et al., 2007), a majority of the error regions were found in control networks, including the cingulo-opercular and frontoparietal networks, although error-related activity was not limited to these networks (Fig. 6). Interestingly, error-related activity does not appear to fill completely any particular network (Fig. 6), rather error-related regions comprise a subset of each network. Moreover, regions within each network appear to be organized based on functional correlations at rest, where regions of a particular network (e.g., frontoparietal regions in yellow) are "close together" in graph space (i.e., stronger functional relationships; Fig. 7B). As will be discussed in more detail below, the regions within a network tended to show one type of error response (e.g., cingulo-opercular shows a fast profile, cerebellum shows a prolonged profile; Fig. 7C).

However, one notable network (frontoparietal) contains both fast and prolonged regions; a distinction that seems to be related to hemisphere (i.e., frontoparietal regions in the left hemisphere were mostly fast, whereas those in the right hemisphere were all prolonged). The purpose of this lateralization, and why it is only evident in the frontoparietal network, is unclear. However, previous work has suggested a laterality of some frontoparietal control-related signals (Dosenbach et al., 2006), specifically a left prefrontal cortex role in earlier processes, such as task setting, and a right prefrontal cortex role in performance monitoring throughout the task (Stuss, 2011). There are other potentially related hemisphere effects (visuospatial neglect) that appear to be consistently of the left hemifield (i.e., right hemisphere).

The notion that error-related activity spans different functional networks is not entirely novel. Previous work has shown a distinction between task control networks, and that both cingulo-opercular and frontoparietal networks show errorrelated control signals (Dosenbach et al., 2008; Power and Petersen, 2013). The current findings extend this work by showing that the error-related regions extend beyond the control networks. We propose that the spatial distribution of error-related regions suggests that there is not a singular functional error network in the brain, related to task control or otherwise, that is responsible for processing error-related information. Instead, error-related activity is implemented by a set of subsystems that are distributed across regions and networks.

\section{Error-related regions are temporally distinct}

One interesting aspect of the error regions identified here is that they appear to process error-related information with different temporal profiles suggesting that there are multiple timescales at which error information is processed or used. Using hierarchical clustering, we identified three distinct response profiles.

Nineteen regions showed a fast response errors, where the time course returned to baseline a few frames after peaking (Fig. $3 B$ ). Comprising this cluster are both "bottom-up" sensory (visual) regions, and "top-down" control regions in cinguloopercular and frontoparietal networks. Our laboratory has shown that the cingulo-opercular and frontoparietal brain networks comprise task control mechanisms, including performance feedback in response to errors (Dosenbach et al., 2006, 2007, for review, see 2008). The timing of the fast profile suggests that these signals act to implement adaptive task control, contributing to successful performance from one trial to the next (or a small number of 
trials). It is worth mentioning that, though in the broader context of task control, the cingulo-opercular network shows sustained activity supporting task maintenance (Dosenbach et al., 2006, 2007), that does not necessarily mean that another type of control signal (errors) in those regions must operate on a prolonged timescale. Here, we show that the cinguloopercular network operates on a fast timescale in response to errors, despite its sustained response throughout the task block. Finally, given that goal-directed behavior requires an ability to recognize appropriate responses and flexibly adjust behavior in response to an error (Ridderinkhof et al., 2004), these responses are potentially related to short-term behavioral consequences including posterror slowing (Rabbitt, 1966; Hester et al., 2012).

Sixteen regions showed a prolonged response profile. These time courses took more than twice as long to return to baseline compared with fast regions (Fig. 3C), suggesting that these error responses represent a more long-term adjustment of task parameters (i.e., implementing control across multiple trials). Comprising this cluster are cerebellar regions, as well as ventral attention and top-down control regions in right frontoparietal and salience networks. With regard to the cerebellum, this profile is consistent with the idea that the cerebellum is critical for iterative learning strategies, where adaptation is required for achieving successful performance after a number of trials (Martin et al., 1996a,b; Norris et al., 2011). Also, previous work suggests a role for right prefrontal cortex in performance monitoring throughout the task, in contrast to earlier processes in left prefrontal cortex (Stuss, 2011). Many of these prolonged regions have been overlooked in previous examinations of error-related activity. Having now been identified, future work could directly assess the functional role of these regions in the context of errors in specific tasks.

Four regions in the putamen form the final cluster. In contrast to the other two clusters, this profile showed no apparent difference in the peak magnitude for correct versus error responses. These regions showed early activity for correct trials (perhaps related to reward signals of accurate performance), followed by a peak for error trials that starts well beyond the target trial (i.e., the onset of the error time course begins only after 6 frames; Fig. 3D).

Support for these task-based profile distinctions is provided by rest-based functional correlations that were naive to the task effects. Regions of a particular profile (Fig. $7 A$, prolonged regions in green) are close together in graph space (i.e., stronger functional relationships), suggesting that they have some functional relationship at rest. So, although the error regions, even within a single response profile, are distributed across different networks (Table 2), the resting connectivity data show that these distrib-
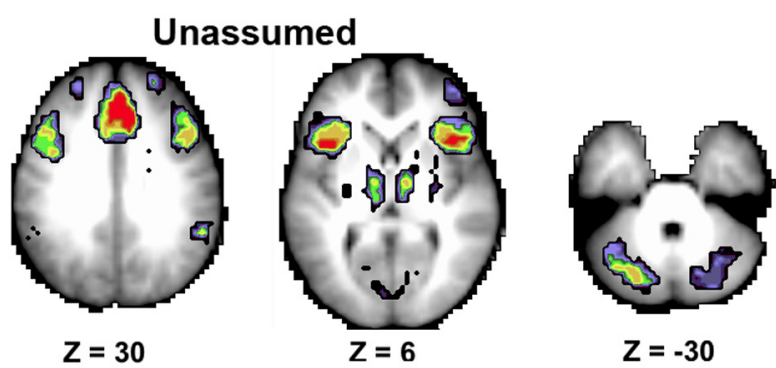

\section{Assumed}
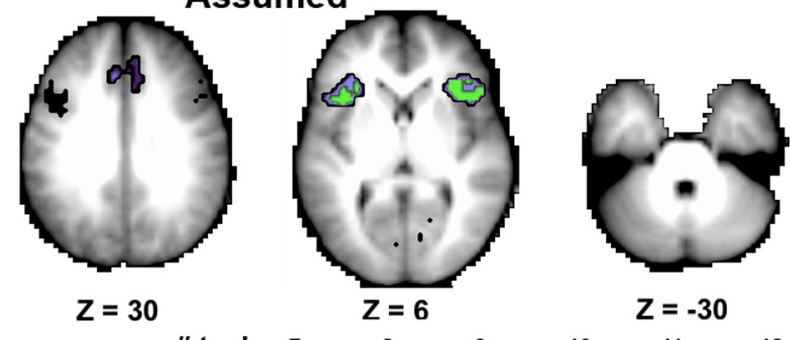

$Z=-\mathbf{3 0}$

\# tasks: 7

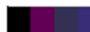

10

11 12

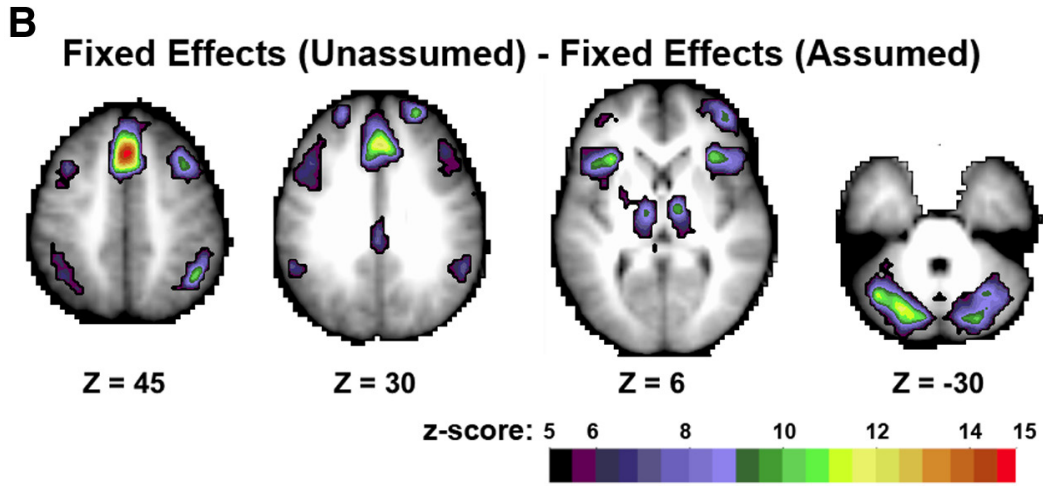

Figure 5. A, A consensus map of regions that showed differential activity between error and correct trials on at least seven tasks. map is shown for an unassumed shape and an assumed shape. $\boldsymbol{B}$. We made a fixed effects statistical $z$-map of the 12 tasks difference between those two (unassumed - assumed). There were no negative values (i.e., no voxels where values were greater for assumed than unassumed shape).

uted regions appear to have stronger functional relationships within profile than across profiles (Fig. $7 C$ ). Next, there is an extra layer of organization based on response profile: delayed regions were strongly related to fast regions, which were strongly related to prolonged (but delayed regions had very weak relationships with prolonged). This suggests that delayed and prolonged regions may function quite independently. Further, with one exception (frontoparietal), each functional network carries its own distinct profile (e.g., cingulo-opercular is fast, cerebellum is prolonged), suggesting a relationship between error-related activity and restingstate functional networks. Together, there appear to be many kinds of relationships that organize this set of error regions.

Finally, there were temporal distinctions in error-related activity between regions within constrained cortical areas. For example, there was an anterior-posterior distinction in response profiles in several areas (e.g., dACC, inferior frontal cortex), where more anterior regions tended to be prolonged, and more posterior regions tended to be fast. This is consistent with previous work (Paulesu et al., 1997; Bush et al., 2000; Picard and Strick, 2001; Chein et al., 2002; Nachev et al., 2005), including differences in temporal profiles (Cannestra et al., 2000), and those 


\section{A Left Hemisphere}
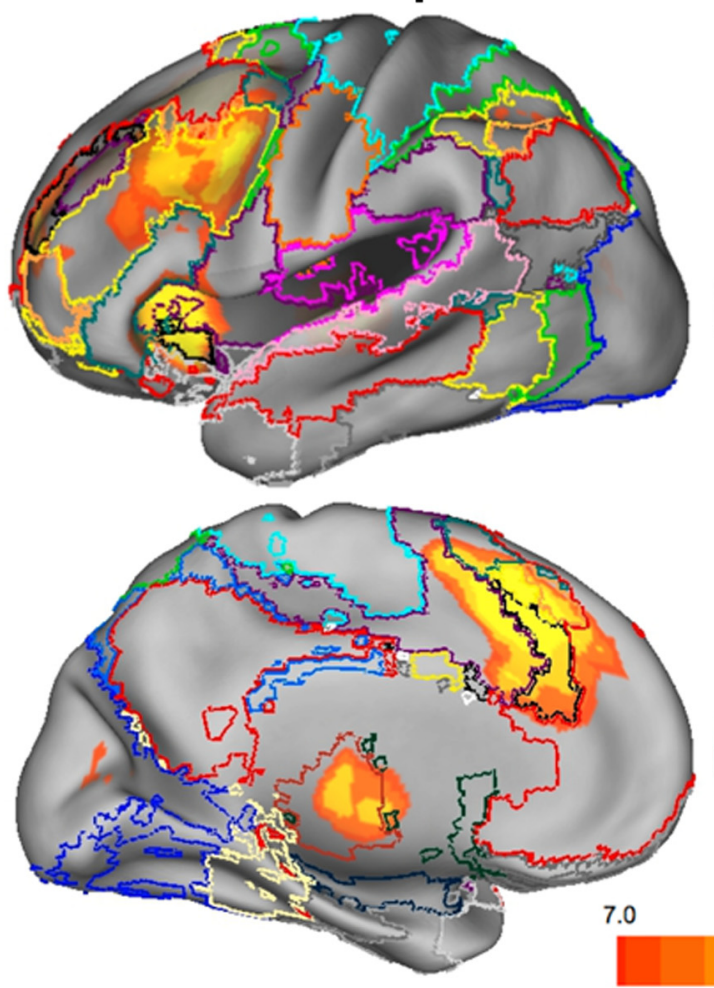

O Frontoparietal

- Cingulo-opercular

- Salience

○ Parietal

\section{Right Hemisphere}
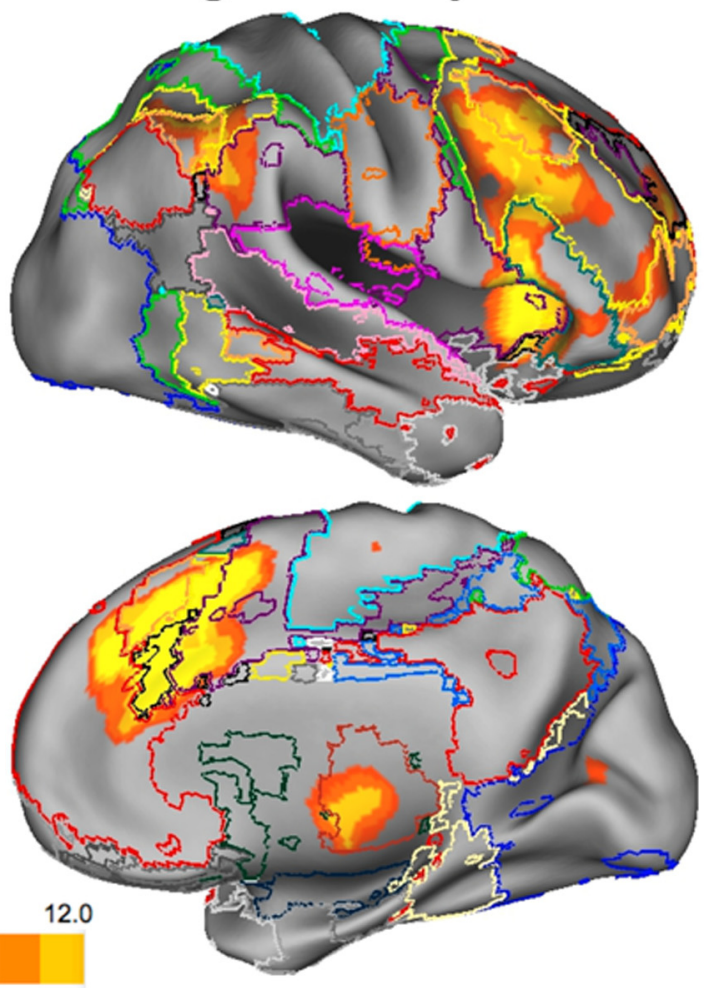

- Ventral Attention

- Visual

- Thalamus

- Subcortical
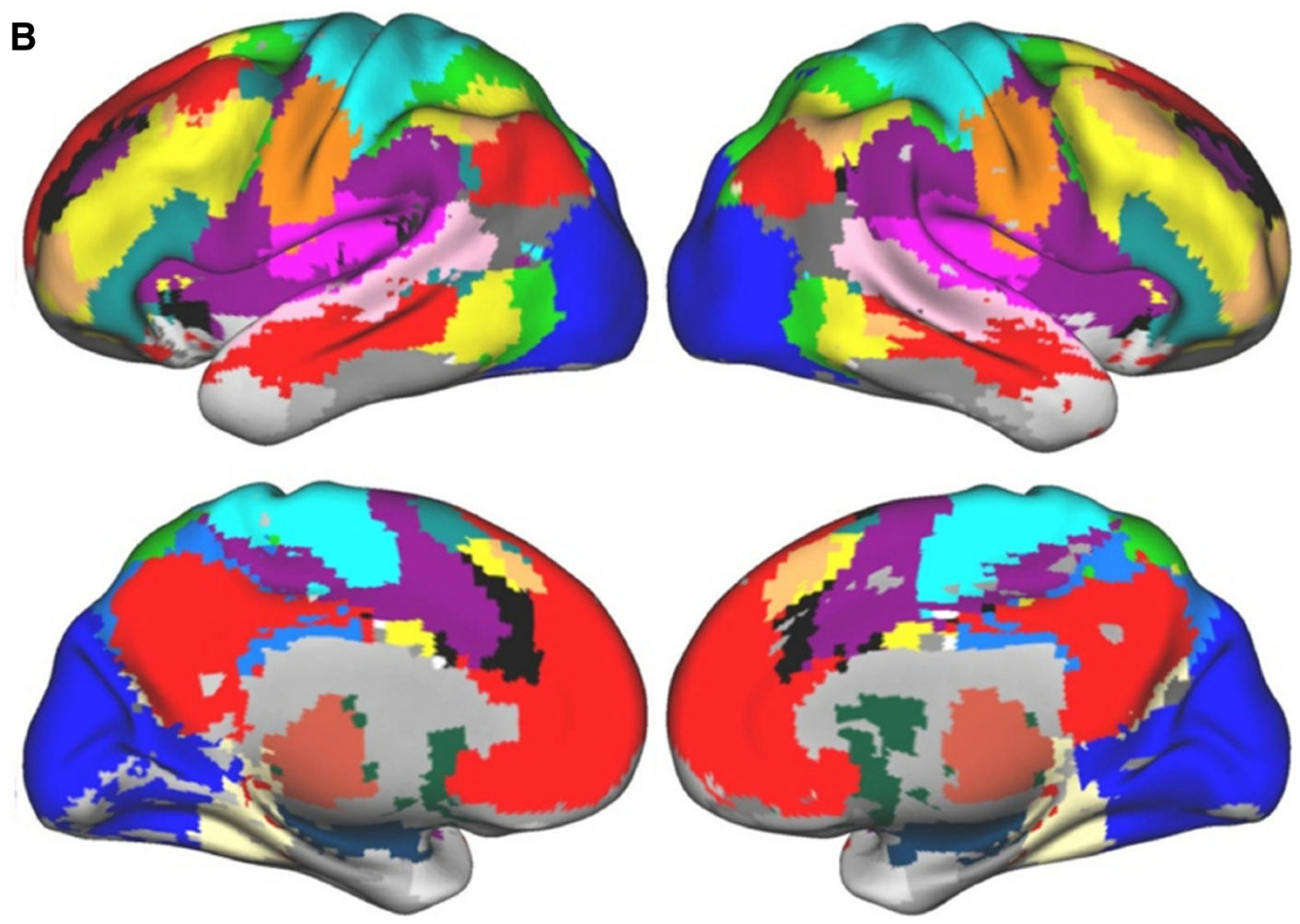
A Regions by Response Profile

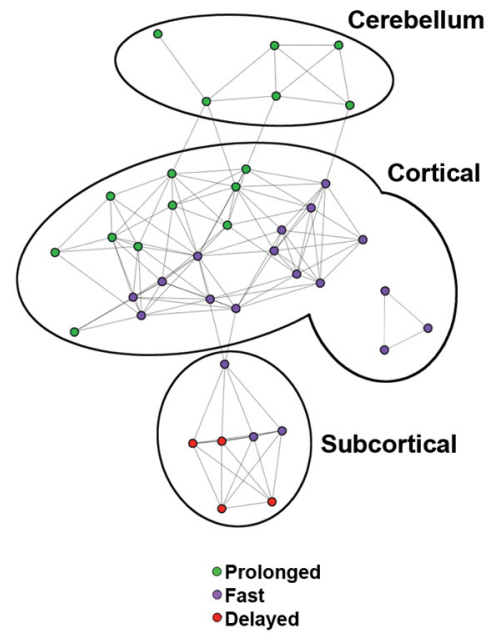

B Regions by Functional Network

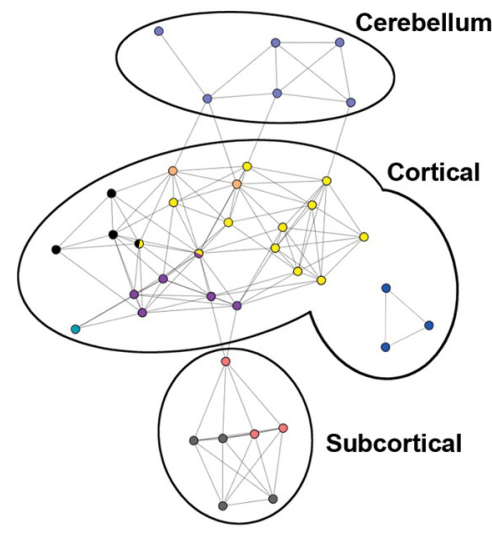

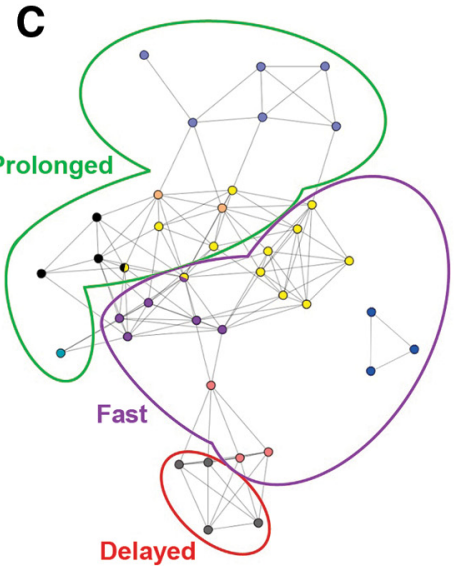

Delayed

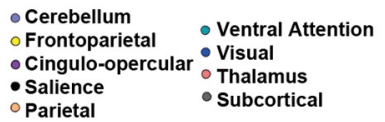

Figure 7. Network analysis graphs using spring-embedding of the $39 \mathrm{ROIs}$ in the three distinct response profiles. $A-C$, Edges, or the connections between the nodes, are defined based on RSFC from a separate set of 120 normal adults. To visualize the network structure, we used a standard technique called spring-embedding, where nodes were repositioned such that high correlations are positioned near one another, and those with weak or no connections are placed more distantly. $A$, Nodes are colored based on the three response profiles (i.e., fast, purple; prolonged, green; delayed, red). Black boundaries are drawn corresponding to general location (cerebellum, cortical, and subcortical regions). Nodes that show the same response profile are highly correlated (i.e., positioned close together). Moreover, delayed nodes are connected with fast, which are, in turn, connected with prolonged (but delayed and prolonged nodes are not directly connected). $\boldsymbol{B}$, Nodes are colored based on predefined functional network assignment (Power et al., 2011). Two nodes are assigned two colors, as they were positioned on the border between two networks (Table 2). The yellow and black node was on the border between frontoparietal and salience networks, and the yellow and purple node was on the border between frontoparietal and cingulo-opercular networks. These colors correspond with boundary colors represented in Figure 6 . Nodes that belong to the same functional network are highly correlated (i.e., positioned close together). $C$, Nodes are colored based on network assignment (as in $\boldsymbol{B}$ ), with circles around the regions of a particular profile (i.e., prolonged regions circled in green, fast regions circled in purple, and delayed regions circled in red). This emphasizes the point that there are multiple functional networks represented in each response profile group, but that, with the exception of the frontoparietal network (yellow nodes) each network shows its own distinct response profile (e.g., cingulo-opercular, thalamus, and visual nodes showed only a fast profile, whereas cerebellum, parietal, salience, and ventral attention nodes showed only a prolonged profile). In contrast, some of the frontoparietal nodes showed a prolonged profile (all in the right hemisphere), whereas others showed a fast profile (all but one were in the left hemisphere).

specifically relevant to error-related processing (Ullsperger and von Cramon, 2001; Rushworth et al., 2004; Mars et al., 2005).

\section{Modeling the response shape provides a more complete representation of error-related activity}

The temporal distinctions in error-related responses highlight the importance of modeling time courses. We compared analyses that used assumed versus unassumed response time courses, and found that most of the "assumed" regions (10 of 11) were detected by the unassumed analyses, but there were many "unassumed" regions (27 of 41 ) that were not detected in the assumed analysis. Most of the 27 regions that were overlooked by the assumed analysis showed a prolonged or delayed response profile, differing from the canonical hemodynamic response shape. In other words, perhaps fMRI studies to date tended to find a specific subset of these error regions (e.g., dACC, anterior insula, intraparietal sulcus, etc.) because they show a fast response profile that more resembles the canonical response shape. Modeling time courses contributes a more complete picture, allowing us not only to identify a broader number of error-related regions,

\section{$\leftarrow$}

Figure 6. $\quad \boldsymbol{A}$, The same consensus map as shown in Figure $1 A$, but with a higher cutoff showing activity (yellow and orange regions) from at least seven tasks. The overlaid boundaries demonstrate the functional networks of the brain, as defined by resting-state data (Power etal., 2011). Error-related activity respects many functional network boundaries (see top left activity in the lateral view of the left hemisphere). However, this activity also spans multiple functional networks. The key below defines relevant functional networks. Two additional networks are shown in the map, but not included in the key because we did not see peak error-related activity here: light green is dorsal attention, and red is default. $\boldsymbol{B}$, The map of functional networks originally presented by Power et al. (2011). but also to organize them based on the timescale of their response (Gonzalez-Castillo et al., 2012 provides a demonstration of how response shape varies across regions, and in a functionally and anatomically meaningful way). Other methods (event-related potentials, lesion studies) have provided evidence suggesting temporal information in performance monitoring (Holroyd et al., 2002; Swick and Turken, 2002; Ullsperger et al., 2002; Mathalon et al., 2003).

\section{Limitations}

There are pros and cons to this meta-analytic approach. Our primary goal was to reveal general features of error processing across many task contexts (types of stimuli, task instructions, and types of errors: omission and commission). Hence, future work is needed to better elucidate the functional interpretations of these spatially and temporally distinct error regions within specific task situations.

Further, we could not completely disentangle responses related to the error trial per se, and those related to downstream effects of the error (e.g., posterror slowing). Thus, it could be that some of the activity reported here is related to the subsequent trial. New evidence suggests that these response profiles replicate in slow event-related designs, which allows for complete separation of individual trials, suggesting they are not (completely) the result of subsequent trial effects.

Next, some tasks resulted in very few errors (Table 1), causing variability in error frequencies across tasks. Importantly, it was not the case that only tasks with more errors showed significant effects of accuracy. Indeed, we found a somewhat surprising effect where tasks with fewer errors showed greater error-related activity in prolonged regions than tasks with more errors. This 
could be associated with greater novelty or error awareness in tasks with fewer errors, but future study is needed to resolve these findings.

Finally, there is some disagreement in the literature as to the resting-state network definitions and nomenclature. For example, our cingulo-opercular network has been referred to as the salience network (Seeley et al., 2007). However, recently, there has been movement toward a consensus across research groups (Power et al., 2011; Yeo et al., 2011), suggesting that the salience and cingulo-opercular networks are distinct. Our work has distinguished several control networks (i.e., salience, cinguloopercular, frontoparietal) that play somewhat separate roles in the service of task control (Power and Petersen, 2013). The current study identified error-related activity in each of these separate networks. Having said that, we emphasize that, independent of nomenclature, the present work highlights that error-related activity is not constrained to a specialized functional network purely dedicated to error-related processes.

\section{Conclusions}

Instead of a single localized error-processing system, we discovered a subset of regions within each of the brain's control networks that provide error-related information to the network. Our findings point to a set of error components within many different functional networks, or systems, and operating on different timescales.

\section{Notes}

Supplemental material for this article is available at http://www.nil.wustl. edu/labs/petersen/Resources.html. New evidence suggests that the response profiles described here replicate in slow event-related designs, which allows for complete separation of individual trials, and thus, these response profiles are not (completely) the result of subsequent trial effects. This material has not been peer reviewed.

\section{References}

Bender-deMoll S, McFarland DA (2006) The art and science of dynamic network visualization. J Soc Struct 7.

Biswal B, Yetkin FZ, Haughton VM, Hyde JS (1995) Functional connectivity in the motor cortex of resting human brain using echo-planar MRI. Magn Reson Med 34:537-541. CrossRef Medline

Bush G, Luu P, Posner MI (2000) Cognitive and emotional influences in anterior cingulate cortex. Trends Cogn Sci 4:215-222. CrossRef Medline

Cannestra AF, Bookheimer SY, Pouratian N, O'Farrell A, Sicotte N, Martin NA, Becker D, Rubino G, Toga AW (2000) Temporal and topographical characterization of language cortices using intraoperative optical intrinsic signals. Neuroimage 12:41-54. CrossRef Medline

Carp J, Kim K, Taylor SF, Fitzgerald KD, Weissman DH (2010) Conditional differences in mean reaction time explain effects of response congruency, but not accuracy, on posterior medial frontal cortex activity. Front Hum Neurosci 4:231. CrossRef Medline

Cassidy B, Solo V (2012) fMRI model diagnostics for the double gamma and temporal derivative. Biomedical Imaging (ISBI), 2012 9th IEEE International Symposium 30-33.

Chein JM, Fissell K, Jacobs S, Fiez JA (2002) Functional heterogeneity within Broca's area during verbal working memory. Physiol Behav 77: 635-639. CrossRef Medline

Church JA, Wenger KK, Dosenbach NU, Miezin FM, Petersen SE, Schlaggar BL (2009) Task control signals in pediatric Tourette syndrome show evidence of immature and anomalous functional activity. Front Hum Neurosci 3:38. CrossRef Medline

Cordes D, Haughton V, Carew JD, Arfanakis K, Maravilla K (2002) Hierarchical clustering to measure connectivity in fMRI resting-state data. Magn Reson Imaging 20:305-317. CrossRef Medline

Danielmeier C, Ullsperger M (2011) Post-error adjustments. Front Psychol 2:233. CrossRef Medline

Danielmeier C, Eichele T, Forstmann BU, Tittgemeyer M, Ullsperger M (2011) Posterior medial frontal cortex activity predicts post-error adap- tations in task-related visual and motor areas. J Neurosci 31:1780-1789. CrossRef Medline

Dehaene S, Posner MI, Tucker DM (1994) Localization of a neural system for error detection and compensation. Psychol Sci 5:303-305. CrossRef

Donaldson DI, Wheeler ME, Petersen SE (2010) Remember the source: dissociating frontal and parietal contributions to episodic memory. J Cogn Neurosci 22:377-391. CrossRef Medline

Dosenbach NU, Visscher KM, Palmer ED, Miezin FM, Wenger KK, Kang HC, Burgund ED, Grimes AL, Schlaggar BL, Petersen SE (2006) A core system for the implementation of task sets. Neuron 50:799-812. CrossRef Medline

Dosenbach NU, Fair DA, Miezin FM, Cohen AL, Wenger KK, Dosenbach RA, Fox MD, Snyder AZ, Vincent JL, Raichle ME, Schlaggar BL, Petersen SE (2007) Distinct brain networks for adaptive and stable task control in humans. Proc Natl Acad Sci U S A 104:11073-11078. CrossRef Medline

Dosenbach NU, Fair DA, Cohen AL, Schlaggar BL, Petersen SE (2008) A dual-networks architecture of top-down control. Trends Cogn Sci 12:99105. CrossRef Medline

Dubis JW, Siegel JS, Neta M, Visscher KM, Petersen SE (2014) Tasks driven by perceptual information do not recruit sustained BOLD activity in cingulo-opercular regions. Cereb Cortex. Advance online publication. doi:10/1093/cercor/bhu187. CrossRef Medline

Fox MD, Snyder AZ, Barch DM, Gusnard DA, Raichle ME (2005) Transient BOLD responses at block transitions. Neuroimage 28:956-966. CrossRef Medline

Gonzalez-Castillo J, Saad ZS, Handwerker DA, Inati SJ, Brenowitz N, Bandettini PA (2012) Whole-brain, time-locked activation with simple tasks revealed using massive averaging and model-free analysis. Proc Natl Acad Sci U S A 109:5487-5492. CrossRef Medline

Greicius MD, Supekar K, Menon V, Dougherty RF (2009) Resting-state functional connectivity reflects structural connectivity in the default mode network. Cereb Cortex 19:72-78. CrossRef Medline

Handl J, Knowles J, Kell DB (2005) Computational cluster validation in post-genomic data analysis. Bioinformatics 21:3201-3212. CrossRef Medline

Hester R, Fassbender C, Garavan H (2004) Individual differences in error processing: a review and reanalysis of three event-related fMRI studies using the GO/NOGO task. Cereb Cortex 14:986-994. CrossRef Medline

Hester R, Nandam LS, O'Connell RG, Wagner J, Strudwick M, Nathan PJ, Mattingley JB, Bellgrove MA (2012) Neurochemical enhancement of conscious error awareness. J Neurosci 32:2619-2627. CrossRef Medline

Holroyd CB, Coles MG (2002) The neural basis of human error processing: reinforcement learning, dopamine, and the error-related negativity. Psychol Rev 109:679-709. CrossRef Medline

Holroyd CB, Dien J, Coles MG (1998) Error-related scalp potentials elicited by hand and foot movements: evidence for an output-independent errorprocessing system in humans. Neurosci Lett 242:65-68. CrossRef Medline

Holroyd CB, Nieuwenhuis S, Yeung N, Nystrom L, Mars RB, Coles MG, Cohen JD (2004) Dorsal anterior cingulate cortex shows fMRI response to internal and external error signals. Nat Neurosci 7:497-498. CrossRef Medline

Kiehl KA, Liddle PF, Hopfinger JB (2000) Error processing and the rostral anterior cingulate: an event-related fMRI study. Psychophysiology 37: 216-223. CrossRef Medline

King JA, Korb FM, von Cramon DY, Ullsperger M (2010) Post-error behavioral adjustments are facilitated by activation and suppression of taskrelevant and task-irrelevant information processing. J Neurosci 30: 12759-12769. CrossRef Medline

Lancaster JL, Glass TG, Lankipalli BR, Downs H, Mayberg H, Fox PT (1995) A modality-independent approach to spatial normalization of tomographic images of the human brain. Hum Brain Mapp 3:209-223. CrossRef

Logan GD, Gordon RD (2001) Executive control of visual attention in dualtask situations. Psychol Rev 108:393-434. CrossRef Medline

Mars RB, Coles MG, Grol MJ, Holroyd CB, Nieuwenhuis S, Hulstijn W, Toni I (2005) Neural dynamics of error processing in medial frontal cortex. Neuroimage 28:1007-1013. CrossRef Medline

Martin TA, Keating JG, Goodkin HP, Bastian AJ, Thach WT (1996a) Throwing while looking through prisms: I. Focal olivocerebellar lesions impair adaptation. Brain 119:1183-1198. CrossRef Medline

Martin TA, Keating JG, Goodkin HP, Bastian AJ, Thach WT (1996b) 
Throwing while looking through prisms: II. Specificity and storage of multiple gaze-throw calibrations. Brain 119:1199-1211. CrossRef Medline

Mathalon DH, Whitfield SL, Ford JM (2003) Anatomy of an error: ERP and fMRI. Biol Psychol 64:119-141. CrossRef Medline

Michelon P, Snyder AZ, Buckner RL, McAvoy M, Zacks JM (2003) Neural correlates of incongruous visual information: an event-related fMRI study. Neuroimage 19:1612-1626. CrossRef Medline

Miezin FM, Maccotta L, Ollinger JM, Petersen SE, Buckner RL (2000) Characterizing the hemodynamic response: effects of presentation rate, sampling procedure, and the possibility of ordering brain activity based on relative timing. Neuroimage 11:735-759. CrossRef Medline

Mugler JP 3rd, Brookeman JR (1990) Three-dimensional magnetizationprepared rapid gradient-echo imaging (3D MP RAGE). Magn Reson Med 15:152-157. CrossRef Medline

Nachev P, Rees G, Parton A, Kennard C, Husain M (2005) Volition and conflict in human medial frontal cortex. Curr Biol 15:122-128. CrossRef Medline

Nelson SM, Dosenbach NU, Cohen AL, Wheeler ME, Schlaggar BL, Petersen SE (2010) Role of the anterior insula in task-level control and focal attention. Brain Struct Funct 214:669-680. CrossRef Medline

Neta M, Schlaggar BL, Petersen SE (2014) Separable responses to error, ambiguity, and reaction time in cingulo-opercular task control regions. Neuroimage 99:59-68. CrossRef Medline

Newman ME (2006) Modularity and community structure in networks. Proc Natl Acad Sci U S A 103:8577-8582. CrossRef Medline

Norris SA, Hathaway EN, Taylor JA, Thach WT (2011) Cerebellar inactivation impairs memory of learned prism gaze-reach calibrations. J Neurophysiol 105:2248-2259. CrossRef Medline

Ojemann JG, Akbudak E, Snyder AZ, McKinstry RC, Raichle ME, Conturo TE (1997) Anatomic localization and quantitative analysis of gradient refocused echo-planar fMRI susceptibility artifacts. Neuroimage 6:156167. CrossRef Medline

Orr JM, Weissman DH (2009) Anterior cingulate cortex makes 2 contributions to minimizing distraction. Cereb Cortex 19:703-711. CrossRef Medline

Paulesu E, Goldacre B, Scifo P, Cappa SF, Gilardi MC, Castiglioni I, Perani D, Fazio F (1997) Functional heterogeneity of left inferior frontal cortex as revealed by fMRI. Neuroreport 8:2011-2017. CrossRef Medline

Petersen SE, Posner MI (2012) The attention system of the human brain: 20 years after. Annu Rev Neurosci 35:73-89. CrossRef Medline

Picard N, Strick PL (2001) Imaging the premotor areas. Curr Opin Neurobiol 11:663-672. CrossRef Medline

Posner MI, Petersen SE (1990) The attention system of the human brain. Annu Rev Neurosci 13:25-42. CrossRef Medline

Power JD, Petersen SE (2013) Control-related systems in the human brain. Curr Opin Neurobiol 23:223-228. CrossRef Medline

Power JD, Cohen AL, Nelson SM, Vogel AC, Church JA, Barnes KA, Wig GS, Laumann TO, Miezin FM, Schlaggar BL, Petersen SE (2011) Functional network organization in the human brain. Neuron 72:665-678. CrossRef Medline

Power JD, Barnes KA, Snyder AZ, Schlaggar BL, Petersen SE (2012) Spurious but systematic correlations in functional connectivity MRI networks arise from subject motion. Neuroimage 59:2142-2154. CrossRef Medline

Power JD, Barnes KA, Snyder AZ, Schlaggar BL, Petersen SE (2013) Steps toward optimizing motion artifact removal in functional connectivity MRI; a reply to carp. Neuroimage 76:439-441. CrossRef Medline

Rabbitt PM (1966) Errors and error correction in choice-response tasks. J Exp Psychol 71:264-272. CrossRef Medline

Ridderinkhof KR, Ullsperger M, Crone EA, Nieuwenhuis S (2004) The role of the medial frontal cortex in cognitive control. Science 306:443-447. CrossRef Medline

Rushworth MF, Walton ME, Kennerley SW, Bannerman DM (2004) Action sets and decisions in the medial frontal cortex. Trends Cogn Sci 8:410417. CrossRef Medline

Salvador R, Suckling J, Coleman MR, Pickard JD, Menon D, Bullmore E (2005) Neurophysiological architecture of functional magnetic resonance images of human brain. Cereb Cortex 15:1332-1342. CrossRef Medline

Seeley WW, Menon V, Schatzberg AF, Keller J, Glover GH, Kenna H, Reiss AL, Greicius MD (2007) Dissociable intrinsic connectivity networks for salience processing and executive control. J Neurosci 27:2349-2356. CrossRef Medline

Shmuel A, Leopold DA (2008) Neuronal correlates of spontaneous fluctuations in fMRI signals in monkey visual cortex: implications for functional connectivity at rest. Hum Brain Mapp 29:751-761. CrossRef Medline

Snyder AZ (1996) Difference image vs ratio image error function forms in PET-PET realignment. In: Quantification of brain function using PET(Myer R, et al., eds), pp 131-137. San Diego: Academic.

Stuss DT (2011) Functions of the frontal lobes: relation to executive functions. J Int Neuropsychol Soc 17:759-765. CrossRef Medline

Swick D, Turken AU (2002) Dissociation between conflict detection and error monitoring in the human anterior cingulate cortex. Proc Natl Acad Sci U S A 99:16354-16359. CrossRef Medline

Talairach J, Tournoux P (1988) Co-planar stereotaxic atlas of the human brain. New York: Thieme Medical.

Tunik E, Frey SH, Grafton ST (2005) Virtual lesions of the anterior intraparietal area disrupt goal-dependent on-line adjustments of grasp. Nat Neurosci 8:505-511. CrossRef Medline

Ullsperger M, von Cramon DY (2001) Subprocesses of performance monitoring: a dissociation of error processing and response competition revealed by event-related fMRI and ERPs. Neuroimage 14:1387-1401. CrossRef Medline

Ullsperger M, von Cramon DY, Müller NG (2002) Interactions of focal cortical lesions with error processing: evidence from event-related brain potentials. Neuropsychology 16:548-561. CrossRef Medline

Ullsperger M, Harsay HA, Wessel JR, Ridderinkhof KR (2010) Conscious perception of errors and its relation to the anterior insula. Brain Struct Funct 214:629-643. CrossRef Medline

van Driel J, Ridderinkhof KR, Cohen MX (2012) Not all errors are alike: theta and alpha EEG dynamics relate to differences in error-processing dynamics. J Neurosci 32:16795-16806. CrossRef Medline

Van Essen DC (2005) A population-average, landmark- and surface-based (PALS) atlas of human cerebral cortex. Neuroimage 28:635-662. CrossRef Medline

Van Essen DC, Drury HA, Dickson J, Harwell J, Hanlon D, Anderson CH (2001) An integrated software suite for surface-based analyses of cerebral cortex. J Am Med Inform Assoc 8:443-459. CrossRef Medline

Wessel JR, Danielmeier C, Morton JB, Ullsperger M (2012) Surprise and error: common neuronal architecture for the processing of errors and novelty. J Neurosci 32:7528-7537. CrossRef Medline

Wheeler ME, Shulman GL, Buckner RL, Miezin FM, Velanova K, Petersen SE (2006) Evidence for separate perceptual reactivation and search processes during remembering. Cereb Cortex 16:949-959. CrossRef Medline

Yeo BT, Krienen FM, Sepulcre J, Sabuncu MR, Lashkari D, Hollinshead M, Roffman JL, Smoller JW, Zöllei L, Polimeni JR, Fischl B, Liu H, Buckner RL (2011) The organization of the human cerebral cortex estimated by intrinsic functional connectivity. J Neurophysiol 106:1125-1165. CrossRef Medline 